
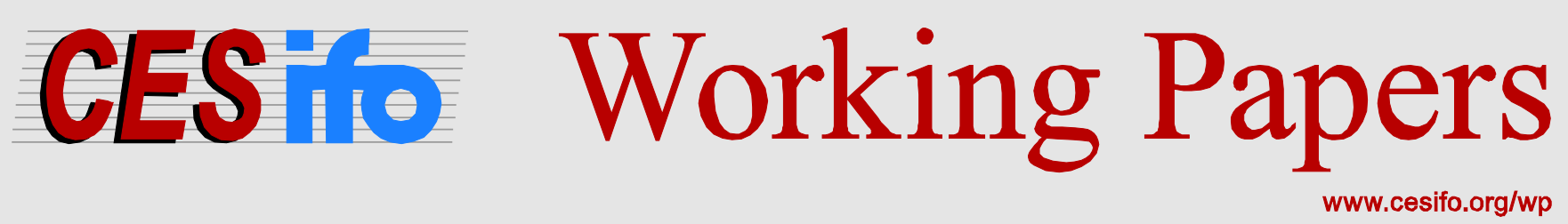

\title{
Institutional Reform and Depositors' Portfolio Choice Evidence from Censored Quantile Regressions
}

\author{
Michael Berlemann \\ Marc-André Luik
}

CESIFO WORKING PAPER NO. 4782

CATEGORY 7: MONETARY POLICY AND INTERNATIONAL FinANCE MAY 2014
An electronic version of the paper may be downloaded
- from the SSRN website: Www.SSRN.com
- from the RePEc website: Www.RePEc.org
- from the CESifo website: www.CESifo-group.org/wp

\section{CESifo}




\title{
Institutional Reform and Depositors’ Portfolio Choice Evidence from Censored Quantile Regressions
}

\begin{abstract}
In this paper we study the effect of institutional reform on the decision to hold risky assets at the extensive and the intensive margin. We therefore make use of the natural experiment of German Division and Reunification and, based on savings bank customer data from German savings banks, study whether the customers of East German banks differ from their West German counterparts. While we find only slight differences in the decision to hold risky assets at the extensive margin, the differences turn out to be much larger at the intensive margin. Moreover, the latter effects turn out to be quite persistent even in the age group of individuals which were too young at the time of German Reunification to have collected financial experiences in one of the previously existing systems. Our results support the view that reforms allowing individuals to get easy access to financial markets quite quickly result in increasing market participation. However, the degree and sort of risk, individuals are willing to bear, seems to change only slowly as the portfolios of East and West German savings bank customers still differ considerably 15 years after German Reunification. We attribute this finding to the only slowly changing informal institutions.
\end{abstract}

JEL-Code: G210, J100, L100, O160, P360.

Keywords: institutional reform, stockholding puzzle, portfolio choice, bank data.

\author{
Michael Berlemann* \\ Helmut-Schmidt-University \\ Department of Economics and \\ Social Sciences \\ Holstenhofweg 85 \\ Germany - 22043 Hamburg \\ michael.berlemann@hsu-hh.de
}

\author{
Marc-André Luik \\ Helmut-Schmidt-University \\ Department of Economics and \\ Social Sciences \\ Holstenhofweg 85 \\ Germany - 22043 Hamburg \\ luikma@hsu-hh.de
}

*corresponding author 


\section{Introduction}

Since Adam Smith the question which factors determine the wealth of nations has been a central issue of economic research. Several waves of theories of economic growth have shaped our understanding of the process of factor accumulation. All these theories have in common that they explain discrepancies in the growth performance between countries by differences in factor endowments and/or differences in preferences (Acemoglu, Johnson and Robinson, 2005). Although North and Thomas (1973) emphasized quite early the fundamental role of institutions in explaining differences in factor accumulation and, thus, in explaining comparative economic growth, formal and informal institutions for a long time have been neglected as determinants of economic development. Nowadays, the picture has changed considerably. Many economists believe that good institutions are important prerequisites for economic prosperity. This belief is guided by the theoretical reasoning of New Institutional Economics ${ }^{2}$ and supported by a growing body of empirical research. ${ }^{3}$

Provided the quality of institutions is a major determinant of economic development, poor and underdeveloped countries might promote their situations by improving their institutions. In fact, many countries around the globe initiated institutional reforms, although with quite differing success (Andrews, 2013). Economic outcomes are shaped by both formal and informal institutions. As governments can only change formal institutions it is an intriguing question how changes in formal institutions affect informal institutions. In this paper we contribute to this line of research by analyzing whether and how quickly the transformation of a formerly planned economy toward a capitalist market economy affects portfolio choices of individuals. This question is important because of two reasons.

First, financial sector development in general is often seen as a prerequisite for economic growth (Levine, 1997). Investment behaviour of private individuals has a significant influence on financial sector development. In economies where property rights are poorly protected and contract enforcement possibilites are bad, the incentives for loan activities are typically limited (Chinn and Ito, 2006), which might prevent the development of an effective banking system. Moreover, weak institutions might deter private individuals from taking part in the stock market. As liquid stock markets facilitate the possibilites to trade ownership and to diversify portfolios (Hasan, Wachtel and Zhou, 2009) the existence of effective stock markets might be seen as an important determinant of economic growth. Chinn and Ito (2006), Rousseau and Wachtel (2000) and Rousseau and Xiao (2007) provide supporting evidence for this line of argument. Second, the question how quickly the transformation of a formerly planned economy toward a market economy affects portfolio choices of individuals is highly relevant as many central and east Europan countries started reforming their formal institutions in the aftermath of the fall of the iron curtain in the late 20th century. ${ }^{4}$ When the Soviet Union was dissolved, 15 sovereign states evolved in Central and Eastern Europe. Most of them

\footnotetext{
${ }^{2}$ For an overview on the most important theoretical arguments see Acemoglu, Johnson and Robinson (2005).

${ }^{3}$ See, among others, e.g. Knack and Keefer (1995), Barro (1996), Knack and Keefer (1997), Levine (1998), LaPorta et al. (1999), Acemoglu, Johnson and Robinson (2001) and Rodrick, Subramanian and Trebbi (2004).

${ }^{4}$ As Williamson (1996) argues, creating effective institutions governing economic transactions was the major task to be solved within the transformation process of these countries.
} 
initiated transformation processes towards market economies and thus opted for economic systems which are in stark contrast to the earlier implemented centrally planned economies. Moreover, most of the the Central and East European transition countries aimed at introducing multi-party democracies. While a significant share of these countries such as Poland, the Czech Republic or the Baltic states introduced these reforms quite quickly and even became members of the European Union, others followed later or are still on their way to decide on these reforms (as currently the Ukraine). Understanding how and how quickly individuals change their portfolio behaviour in response to changes in formal institutions is helpful to forecast and evaluate the transformation process in the referring countries. However, the results of our analysis go well beyond the case of transition countries, as many institutional reforms in other poorly performing countries also focus on improving economically relevant institutions.

The existing empirical evidence on the effects of reforms of formal institutions on individual portfolio choice is yet very scarce. One of the rare exceptions in this respect is the analysis of Osili and Paulson (2008). The authors base their study on individual survey data from the U.S., extracted from the Survey of Income and Program Participation. The survey also contains information on U.S. immigrants and allows identifying their country of origin. Osili and Paulson (2008) argue that immigration can be interpreted similarily as an institutional reform as the immigrants are suddenly confronted with completely different formal institutions while at least initially their attitudes are still shaped by the experiences they made in their countries of origin. The authors find that country-of-origin institutional quality has a strong effect on the likelihood of immigrants' stock market participation. Lower institutional quality in the country of origin turns out to depress the probability to hold stocks significantly. Moreover, the effect is amplified by living in a neighbourhood with many other immigrants from the same country of origin. However, the effect tends to decrease slowly in the course of time and completely diminishes after roughly a quarter of a century living under the new formal institutional framework. Moreover, Osili and Paulson (2008) find no effect of country-of-origin institutions at all for immigrants which have been younger than 16 years when immigrating. Similarly, the authors find no empirical evidence indicating that informal institutions are transmitted to younger generations.

However, it is less clear in how far Osili and Paulson's (2008) results can really answer the question how institutional reforms affect household finance in general. Two major problems render this generalization critical. First, it cannot be ruled out that the sample of emigrants differs considerably from the rest of the population of the country of origin. One might suspect that the emigrants are less risk averse and better educated than the average citizen. Second and even more important, one might suspect that it makes a huge difference whether an individual experiences a change in formal institutions in his country of origin or by moving to a foreign country. In the first case the individual is surrounded by other citizens with the same institutional experiences. As a consequence the whole population has to adapt to the new formal institutions. In the second case, where an individual moves into a different country with stable institutions, the emigrant interacts primarily with people who are already experienced with the prevailing formal institutions. One might therefore expect that in the latter (and for reforms less typical) case former informal rules become unimportant more quickly.

A more suitable framework of studying the effects of institutional reform on household portfolios is provided by 
the natural experiment of German Division and Reunification. For almost 40 years the populations of the two Germanies experienced completely different political, social and economic systems and, thus, have lived under completely different institutions. Using historical data, Alesina and Fuchs-Schündeln (2007) show that before 1945, the regions belonging to East and West Germany were similar regarding their income levels and other economic dimensions, e.g., the share of the population working in industry, agriculture, or commerce. Moreover, historical election results indicate no differences with respect to political views. Thus, differences in informal institutions between the West and the East German population can clearly be attributed to the treatment, i.e. the differences in the formal institutions throughout the period of German Division. In a recent paper, Fuchs-Schündeln and Haliassos (2013) have made use of this setting to study whether product familiarity matters for the decision to hold different types of assets. As East Germans had no experiences with risky financial products such as stocks, bonds or mututal funds one might expect that East Germans exhibit a lower probability to hold these assets in their portfolios. However, based on the panel dataset of the GSOEP survey the authors find no indications that product familiarity matters as product participation rates of East Germans were comparable to those of West Germans of similar characteristics even in the years directly after German Reunification.

In our study of the effects of institutional reform on individual portfolio behaviour we make use of the described natural experiment of German Division. Different from most of the existing studies of individual portfolio choice we base our analysis not on survey information but on a cross-section (2006) of individual customer data from German savings banks, located in both parts of Germany. In a first step we study the determinants of the decision to hold risky assets at the extensive margin. Using a logit estimation approach we find West Germans to exhibit a higher probability to invest in external risky assets while East Germans have a higher probability to invest in risky assets managed by their savings bank. However, broadly in line with the findings of Fuchs-Schündeln and Haliassos (2013), these differences are comparatively small. In the second step we proceed by studying how much East and West German bank customers invest into risky assets. Applying a censored quantile regression approach we find that the differences between East and West Germans are considerably larger at the intensive margin. We find West Germans to hold significantly more external risky assets, even after controlling for differences in their customer characteristics. Moreover, the difference to the East Germans increases in the conditional level of risky external asset holdings. The opposite holds true for risky assets (mutual funds) managed by their own bank. Here, East Germans hold higher levels of assets. However, in the highest conditional quantiles the effect reverses. Thus, our analysis tends to support Osili and Paulson's (2008) finding that informal institutions tend to have long-lasting effects on portfolio behaviour. However, different from Osili and Paulson (2008) we find these effects to exist even in the generation of bank customers which was itself too young at the time of German Reunification to have made its own financial experiences in the former system. Thus, informal institutions seem to be even more persistent as the study of Osili and Paulson (2008) indicates.

The paper is organized as follows. The second section reviews the literature on the determinants of the decision to hold risky assets. The third section introduces the employed dataset, presents some descriptive statistics and describes the sample procedure which is applied to generate the dataset for the subsequent empirical analysis. Section four 
delivers the empirical analysis of the decision to hold risky assets at the extensive margin while section five considers the decision at the intensive margin. In section six we study differences among various different age groups and thus shed some light on the development of formal institutions over the course of time. The final section summarizes the main results and draws conclusions.

\section{Related Literature}

The question how corporations (should) decide on their financial portfolios is a major topic of corporate finance. However, since private households differ substantially from corporations, the results of corporate finance research can hardly be applied to financial decisions of private households (Guiso and Sodini, 2012). First, the group of private individuals is much more diverse than the group of corporations. For example, private individuals differ enormously in factors such as education, profession and financial literacy. The same holds true for individual risk perceptions and risk preferences, which are typically shaped by the institutional environment and the experiences made under this environment. Second, private households care about issues like pensions, bequests and children education. Third, when making investment decisions, individuals face a background risk of becoming unemployed. In the light of these specifics a new strand of the literature, household finance, evolved since the early 1990s (Haliassos, 2008). An important finding of this literature is that much less private households tend to hold risky assets as classic portfolio choice theory (Merton, 1969) predicts, a phenomenon typically referred to as the stockholding puzzle. The literature mostly explains this puzzle by households' participation costs and complementary effects (e.g. Christelis, Georgarakos and Haliassos, 2011). Triggered by the early paper by Haliassos and Bertaut (1995), a quickly growing empirical literature on the determinants of the decision to hold risky assets evolved which shall be summarized briefly in the following.

Many of the variables which have been considered as possible determinants of the decision to hold risky assets are related to the participation costs of individuals in financial markets. Following Vissing-Jorgensen (2002) these costs can be categorized as fixed entry costs, fixed and variable costs and per period trading costs.

Following Alan (2006), entry costs can be thought of as "the value of time spent to understand the basic functioning of stock markets, to learn how to follow price movements, how to trade, how to assess risk and return relationship for an optimal portfolio choice, etc." Whenever an individual wants to take part in the stock market, it has to bear these costs once. Since collecting the necessary information is time consuming, the entry costs should depend on the individual opportunity costs of time. Individuals with higher income should, therefore, face higher entry costs. One might thus conclude that individuals with higher income are less likely to buy risky assets. However, as individuals with higher income can also more easily afford to bear the entry costs, the effect of income on the stockholding decision is typically found to be positive. ${ }^{5}$ A factor contributing to this result might be seen in the fact that individuals often bear these costs early in their life when their income and thus their entry costs are comparatively low.

\footnotetext{
${ }^{5}$ See e.g. Vissing-Jorgensen (2002).
} 
A second important determinant of stock market participation is financial wealth. Similar as individuals with higher income, wealthier individuals can more easily afford the described entry and transaction costs. Financial wealth consists of the value of all financial and real assets. ${ }^{6}$ Most of the existing studies of the participation decision have found a significantly positive effect of financial wealth. ${ }^{7}$

Third, cognitive abilities might have an effect on the stockholding decision. Individuals with better cognitive abilities can more easily and quickly process information. As a consequence, they have lower entry costs and can more cheaply and quickly monitor stock markets. Thus, individuals with higher cognitive abilities should exhibit a higher probability to buy risky assets. This hypothesis is confirmed by the work of Christelis, Jappelli and Padula (2010) on the basis of a cross-country survey which allows to deduct information on respondents' cognitive abilities. Similar as cognitive abilities, higher education might contribute to lower entry and transaction costs and thus to a higher degree of stock market participation. Campbell (2006) and Calvet et al. (2007) find supporting evidence for this hypothesis. As the empirical study for Italy by Guiso and Jappelli (2005) finds, education also increases financial awareness, which itself turns out to have a positive impact on stock market participation. ${ }^{8}$ Financial literacy might be interpreted as a subfield of education. The empirical study by van Rooij, Lusardi and Alessie (2011) for the Netherlands finds the level of financial literacy to be positively related to the probability to hold stocks. To some extent, cognitive abilities, financial literacy and education are also reflected by an individual's occupation, see e.g. Campbell (2006). However, the occupation is also closely related to unemployment and income risks. As an example, Heaton and Lucas (2000) finds that entrepreneurs have a lower probability to own risky financial assets.

Another often considered factor of the participation decision is age. ${ }^{9}$ While age is almost always included in analyses of household portfolios, the exact specification differs from study to study. Some papers include age in a linear fashion. An example is Calvet, Campbell and Sodini (2007), who finds a slightly negative effect of age on the participation decision. Other studies such as Campbell (2006) use a polynomial specification and find a hump-shaped age pattern. The least restrictive way of modeling age effects is the inclusion of age (group) dummies. Employing this approach, Guiso, Haliassos and Jappelli (2003) find supporting evidence for a hump-shaped effect of age on the decision to hold risky assets. Due to the fact that almost all studies use cross-section data, the existing empirical evidence might be subject to an identification problem as it cannot be ruled out that the results are driven by cohort effects. ${ }^{10}$ The common practice of estimating age effects is thus only correct if in fact cohort-specific effects are

\footnotetext{
${ }^{6}$ While liabilities reduce financial wealth, they might nevertheless provide the necessary liquidity to cover stock market participation costs.

${ }^{7}$ See e.g. Haliassos and Bertaut (1995), Börsch-Supan and Eymann (2002), Guiso, Haliassos and Jappelli (2003), Calvet, Campbell and Sodini (2007), Christelis, Georgarakos and Haliassos (2013). The articles in Guiso, Haliassos and Jappelli (2002) provide results for various different countries. Financial wealth has also been found to have an influence on the share of risky assets in investors' portfolios, see King and Leape (1998) and Wachter and Yogo (2010). Carrol (2002) focuses exclusively on wealthy households.

${ }^{8}$ According to the results reported in Guiso and Jappelli (2005) the stock-ownership rate in Italy would almost double whenever potential investors would be aware of all investment opportunities.

${ }^{9}$ Various theoretical papers have argued that age should also have an influence on portfolio composition, see e.g. Gomes and Michaelides (2003), Gomes and Michaelides (2005) and Cocco (2005).

${ }^{10}$ Ameriks and Zeldes (2004).
} 
absent.

Various studies have found that male and female investors exhibit different behavior in financial markets. As an example, Barber and Odean (2001) find that male financial market participants tend to behave overconfidentially and to realize higher trading volumes. One might therefore expect that gender has also an influence on the decision to hold risky assets. In fact, many studies (such as e.g. van Rooij, Lusardi and Alessie, 2011) find gender effects. However, no such effect was detected in Haliassos and Bertaut (1995).

Additional socio-demographic factors which have been considered are ethnicity, marital status and parentship. White individuals show a higher probability of holding risky assets than other ethnicities (see, e.g., Haliassos and Bertaut, 1995)). Being married or having children tends to decrease the willingness to take part in the stock market (Van Rooij, Lusardi and Alessie, 2011). The health status also seems to matter for the decision to hold risky assets. Rosen and Wu (2004) find that households in poor health are less likely to hold risky financial assets. Moreover they find that poor health is associated with a smaller share of financial wealth held in risky assets and a larger share in safe assets.

As discussed earlier, institutional factors likely also play a role in portfolio decisions. Besides the already described study by Osili and Paulson (2008), a number of additional studies have identified relevant institutional factors.

Guiso, Sapienza and Zingales (2004) study the effect of the level of social capital on different aspects of financial development, among them stock market participation. The authors argue that financial contracts are highly trustintensive. Financial contracts, i.e. the exchange of a sum of money today against the promise to return more money in the future, will only be made when the financier trusts the financee. Guiso, Sapienza and Zingales (2004) argue that social capital tends to increase trust in a society and thus should contribute to higher degrees of stock market participation. When using electoral participation and blood donations as proxies for social capital, the authors in fact find strong empirical evidence in favour of their hypothesis, based on survey data for Italian regions. ${ }^{11}$

In a similar vein, Hong, Kubik and Stein (2004) argue, based on a well-defined theoretical model, that sociability might trigger stock market participation. They identify two channels through which social interaction might influence participation: word-of-mouth and observational learning on the one hand and pleasure of being capable of taking part in conversations and discussions on market developments with other fellow participants of the stock market on the other. The theoretical model distinguishes between non-socials, basing their decision to take part in the stock market exclusively on the earlier mentioned individual participation costs, and socials, receiving an extra utility from being surrounded by other stock market participants. The model predicts stock market participation rates among socials to be higher than among non-socials, all else being equal. Based on survey evidence from the Health and Retirement Study (HRS) Hong, Kubik and Stein (2004) study this hypothesis empirically. After classifying the survey respondents into socials and non-socials, based on survey questions on interactions with their neighbours and church attendance, the authors in fact find a strong, robust and statistically significant effect of sociability on stock market participation. ${ }^{12} \mathrm{~A}$

\footnotetext{
${ }^{11}$ In another study Guiso, Sapienza and Zingales (2008) show that general mistrust in people lowers stock market participation.

${ }^{12}$ Georgarakos, Haliassos and Pasini (2013) apply the idea of social interactions to debt behaviour. The authors find that households perceiving
} 
reassessment for German data by Dierkes, Klos and Langer (2011) leads to the result that the effect of sociability on the probability of holding risky assets is much stronger among people younger than 50 years.

In their study of 13 industrialized countries Christelis, Georgarakos and Haliassos (2013) find that there are still considerable differences in stock market participation on the country level after controlling for differences in population characteristics. The authors find that these differences to some extent are related to differences in institutional factors such as shareholder rights and the level of prevailing trust in the referring countries. Both, a higher level of shareholder rights and a higher level of trust tends to increase stock market participation.

\section{Data, Descriptive Statistics and Sampling Procedure}

\subsection{Data}

Up to now, most of the empirical evidence concerning household finance is based on survey evidence. Surveys have the advantage of being capable of drawing a reasonably complete picture of household wealth as it is, in principle, possible to ask for each type of asset and liability separately and regardless of where the assets and liabilities are held (Calvet, Campbell and Sodini, 2007). However, this comes at the price of the well-known disadvantages of questionnaires such as problems of self-selection, non-response behaviour, systematic misreporting, wishful thinking and lack of accuracy. ${ }^{13}$ As an alternative, account data from banks can be used, whenever available. While this sort of data typically exhibits high levels of validity, this comes at the price that account data often do not provide a complete picture of household wealth. For example, households may have multiple accounts or hold parts of their assets and liabilities outside banks.

Our analysis enriches the existing literature by relying on a unique dataset consisting of individual customer data from 11 German savings banks. The banks are either located in rural or in urban areas. Eight banks operate in East Germany, three in West Germany. For all eleven savings banks in our sample we have a complete record of all private customer accounts. We excluded corporate clients from the sample, since corporations are well known to differ in their portfolio behaviour. While the vast majority of accounts in our sample are individual accounts, there is a significant number of joint accounts, typically owned by (married) couples. Since our estimation model bases on individual data, we split up joint accounts by assigning assets and liabilities proportionally to (fictive) individual accounts.

Some observations had to be excluded from the sample. In particular, we excluded all observations of customers having neither assets nor liabilities with their savings bank (56,383 observations). While these customers are in the books of their savings bank, the bank has no active business with them. In order to concentrate on customers which likely hold the major share of their financial wealth with their savings bank, we excluded customers not owning a checking account or having zero asset wealth (584,218 observations). Furthermore, we excluded all observations

themselves as poor tend to borrow more to keep up with their peer groups. A joint analysis of trust and sociability on stock market participation can be found in the work of Georgarakos and Pasini (2011).

${ }^{13}$ For a discussion see Calvet, Campbell and Sodini, 2007, or Guiso and Sodini, 2012. 
which are likely misreported. For example, we deleted customers with unknown age or with a reported age of more than 100 years from the sample (38,030 observations). ${ }^{14}$ Moreover, we drop all observations of customers younger than 18 years (243,868 observations) since these customers, due to legal restrictions, cannot choose their portfolio freely. Ultimately, our sample consists of 1,779,416 customers. While 1,436,221 observations come from the eight East German savings banks, the remaining 343,195 observations are from the three West German savings banks.

Table 1 delivers an overview on the set of variables which is available for each bank customer. The table also provides a brief description of the variables. Three sorts of information are available on the customer level. First, we have some information on socio-demographic information of the bank customers. Second, the dataset contains information on the customers' bank connection. Third, we have information on assets and liabilities the customers hold with their savings banks. All variables are recorded with their values as of 31 December 2006.

The block of sociodemographic variables contains information on a customer's gender, age and the employment status. The variable Male is a dummy for male bank customers. While $54.82 \%$ of the East German savings bank customers are female, the share of female customers is slightly lower in West Germany (52.12\%). A customer's age is coded in two alternative ways. The variable Age reports a customer's age in years. However, we also coded dummy variables $\mathrm{Age}(m)$ for each annual age class $m=18, \ldots 87$. In addition to that we coded a joint dummy for all age classes above the age of 87 . The average age of the savings bank customer in our database is 51.70 years. The average customer of East German savings banks is 52.08 years old and thus slightly less than 2 years older than its West German counterpart (50.13). The dummy variable Transfer reports whether the referring individual received social transfers (such as unemployment benefits).

Besides socio-demographic information we also have information on bank customers' bank affiliations. The dummy variable East describes whether the referring customer belongs to an East or to a West German savings bank. Moreover, we have information on whether the customers are affiliated with a savings bank operating in an urban area or whether it is located in a rural region. Using the classification of the BBSR (2009) we define urban regions as being an "'Urban agglomeration"'. The remaining regions are defined as being rural. For all the latter observations the dummy variable Rural takes the value of one.

The remaining variables describe the customers' portfolios. Our dataset covers the most important types of liabilities and assets. We have data on two different sorts of liabilities. First, the variable Loan comprises all types of loans such as consumer credits or mortgages. Second, the variable Overdraft describes the utilized credit line of the checking account.

The dataset includes data on five different asset classes. ${ }^{15}$ First, we have information on the amount of sight

\footnotetext{
${ }^{14}$ While a small number of customers might in fact be older than 100 years, the data most likely refer to deceased customers, which have not yet been deleted from the databases.

${ }^{15}$ The data was provided by each bank separately. For some banks, even more detailed data on customer accounts was available. However, we had to use the data on the aggregation level which was available for all sample banks. In particular, no consistent information on maturities was available.
} 
Table 1: Description of variables

\begin{tabular}{lll}
\hline Variable & Description & Values \\
\hline Male & Sex of customer & Female $=0$, Male $=1$ \\
East & Bank affiliation of customer & Customer belongs to a West German bank \\
& & $=0$, Customer belongs to an East German \\
& & bank $=1$ \\
Age & Age of customer at reference date & age of customer in years \\
Age(m) & Age of customer at reference date & If customer is of age m, then age $(\mathrm{m})=1$, \\
& & otherwise age $(\mathrm{m})=0 ;$ (m $=18, \ldots, 88+)$ \\
Transfer & Receiving Social Transfer & No $=0$, Yes $=1$ \\
Rural & Bank Location & Urban $=0$, Rural $=1$ \\
Loan & Loans & Value at end of reference period $(€)$ \\
Overdraft & Utilized credit line (checking account) & Value at end of reference period $(€)$ \\
Sightdep & Sight deposits & Value at end of reference period $(€)$ \\
Timedep & Time deposits & Value at end of reference period $(€)$ \\
Savingdep & Savings deposits & Value at end of reference period $(€)$ \\
Risky int & Mutual funds issued by savings bank & Value at end of reference period $(€)$ \\
Risky ext & Stocks, bonds and external mutual & Value at end of reference period $(€)$ \\
Risky tot & Stocks, bonds and mutual funds & Value at end of reference period $(€)$ \\
\hline
\end{tabular}

deposits, a customer holds with his or her bank (Sightdep). Second, the variable Timedep comprises a customer's sum of time deposits. Third, deposits with longer time-horizons, i.e. savings deposits, are summarized in the variable Savingdep. Finally, we have information on the amount of risky assets, customers hold in their bank depots. The dataset allows distinguishing between two sorts of risky assets. For every bank customer we have the the amount of wealth held in mutual funds, issued and managed by DEKA Bank (Risky int), an institution owned by the German savings banks themselves. While bank customers holding this type of assets clearly make an active decision to invest in risky assets, they nevertheless remain passive in deciding in which sort of risky assets they invest. Instead, the holders of DEKA funds delegate this decision to the fund managers of their bank. Finally, we also have information on the amount of wealth, a bank customer holds in shares, bonds and additional mutual funds, issued and managed by external institutions (Risky ext). While this asset group thus also contains a number of mutual funds, bank customers holding wealth in this asset class take over a much more active role than the holders of DEKA funds. The variable Risky tot summarizes all risky investments, i.e. the sum of wealth held in the form of shares, bonds and mutual funds. 
Table 2: Share of Asset Classes in Gross Financial Wealth and Utilization Rates

Germany West East

\begin{tabular}{lcc|cccc} 
Asset & Util. Rate & Share & Util. Rate & Share & Util. Rate & Share \\
\hline \hline Sightdep & 0.91 & 0.19 & 0.90 & 0.18 & 0.94 & 0.24 \\
Savingdep & 0.70 & 0.42 & 0.71 & 0.39 & 0.67 & 0.56 \\
Timedep & 0.04 & 0.07 & 0.05 & 0.09 & 0.00 & 0.00 \\
Risky ext & 0.11 & 0.23 & 0.11 & 0.27 & 0.08 & 0.09 \\
Risky int & 0.12 & 0.08 & 0.11 & 0.07 & 0.14 & 0.11 \\
Loan & 0.15 & - & 0.17 & - & 0.07 & - \\
Overdraft & 0.14 & - & 0.14 & - & 0.13 & - \\
\hline
\end{tabular}

Share is defined as wealth held in the referring asset class divided by gross financial wealth.

The utilization rate is defined as percentage of households holding a specific asset.

\subsection{Descriptive Statistics}

Table 2 delivers a descriptive statistics of portfolio compositions. The table shows utilization rates for various types of assets and liabilities. Moreover, the table reports the share each asset contributes to gross financial wealth. We report average values for East and West German savings bank customers. The reported values for Germany are population-weighted averages of East and West German customers. German savings bank customers tend to hold roughly two thirds of their financial wealth in comparatively safe assets such as sight deposits (19\%), savings deposits (42\%) and time deposits (7\%). While $91 \%$ of all savings bank customers hold positive balances on their checking accounts, $70 \%$ own savings deposits. However, only $4 \%$ of all customers hold time deposits. Interestingly enough, our dataset impressively reproduces the earlier discussed stockholding puzzle. While $31 \%$ of aggregate financial wealth is held in risky assets, only a comparatively small fraction of all bank customers hold risky assets in their portfolios at all. $12 \%$ of all savings bank customers own mutual funds, managed by the subsidiary DEKA Bank. $11 \%$ of customers (but not necessarily the same customers) hold other risky financial assets in his or her investment account (stocks, bonds, external mutual funds etc.).

Table 2 reports remarkable differences between East and West German savings bank customers. While West German bank customers hold 34\% of their financial wealth in risky assets, East German customers hold only $20 \%$ in this asset type. We also find differences in ownership rates of the two different types of risky assets between East and West Germans. While East Germans more often own mutual funds issued by DEKA Bank (14\% versus $11 \%$ in West Germany), they less often hold other risky financial assets such as stocks, bonds and external mutual funds in their portfolios (8\% versus $11 \%$ in West Germany). East and West Germans also differ in their choice of safe assets. East Germans more often make use of their checking accounts but less often hold saving deposits. East Germans almost never hold time deposits while 5\% of West German bank customers do so. Finally, East and West Germans also differ 
Table 3: Conditional Share of Asset Classes in Gross Financial Wealth

Germany West East

\begin{tabular}{lcccc|cc} 
& Share & Share & Share & Share & Share & Share \\
\hline Asset & Risky ext $>0$ & Risky int $>0$ & Risky ext $>0$ & Risky int $>0$ & Risky ext $>0$ & Risky int $>0$ \\
\hline \hline Sightdep & 0.11 & 0.12 & 0.10 & 0.11 & 0.14 & 0.15 \\
Savingdep & 0.22 & 0.30 & 0.18 & 0.28 & 0.37 & 0.38 \\
Timedep & 0.07 & 0.04 & 0.09 & 0.05 & 0.00 & 0.00 \\
Risky ext & 0.52 & 0.22 & 0.56 & 0.25 & 0.35 & 0.11 \\
Risky int & 0.08 & 0.31 & 0.07 & 0.30 & 0.14 & 0.35 \\
\hline
\end{tabular}

Shares conditional on positive wealth in external or internal risky assets class. Shares are calculated based on aggregate gross financial wealth.

Zero values denote a value below $0.1 \%$.

in their liabilities. $17 \%$ of West German customers have credit contracts with their savings banks while this holds true for only $7 \%$ of the East German customers. No obvious differences can be found for the use of the overdraft facility.

Table 3 shows the asset composition of savings bank customers for those customers holding one of the two risky asset classes. The presented data indicate that, whenever an individual invests in risky assets, it invests a significant share of its financial wealth in these assets. As an example, German savings bank customers holding DEKA funds on average hold $31 \%$ of their financial wealth in this type of asset while customers holding external risky assets only hold $8 \%$ in DEKA funds. Similary, bank customers owning external risky assets hold $52 \%$ of their financial wealth in these assets, compared to only $22 \%$ of financial wealth of the owners of DEKA funds.

Table 4 informs on the (conditional) mean and median values of the different types of assets and liabilities of (East and West) German savings bank customers. The often quite large differences between mean and median values indicate strongly asymmetric distributions within the various asset and liability classes. In the lower part of the table we also report gross and net financial wealth. As we might expect, gross financial wealth is higher within West Germany. Somewhat surprising, net financial wealth is higher in East Germany. Obviously, this finding is due to the fact that West Germans tend to have significantly more liabilities, a finding which is consistent with other international studies (see, e.g., Calvet, Campbell and Sodini (2007)). As we have no information on real assets such as real estate, cars or other long-lived consumer goods, the finding that East Germans exhibit higher levels of net financial wealth in our dataset should not be interpreted as an indication that the East German population would in general be more wealthy.

Although we should not necessarily expect that the descriptive results of our dataset coincides with those reported in survey studies, a comparison with the results found in the literature is interesting. In Table 5 we summarize the utilization rates for risky assets found in 5 different scientific studies, concerned with Germany. These studies have in common that they employ survey data. However, they employ different data sources with strongly differing properties. 
Table 4: Mean and Median of Asset Classes Conditional on Utilization

Germany West East

\begin{tabular}{lcccccc} 
Asset $($ in $€)$ & Mean & Median & Mean & Median & Mean & Median \\
\hline \hline Sightdep & 3,585 & 1,257 & 3,636 & 1,190 & 3,385 & 1,519 \\
Savingdep & 10,345 & 2,411 & 10,174 & 2,084 & 11,018 & 3,702 \\
Timedep & 28,319 & 9,321 & 30,981 & 10,000 & 17,821 & 6644 \\
Risky ext & 38,792 & 13,469 & 44,880 & 14,700 & 14,777 & 8,612 \\
Risky int & 11,646 & 4,271 & 12,100 & 4,046 & 9,854 & 5,156 \\
Loan & 39,948 & 17,753 & 45,475 & 20,703 & 18,143 & 6114 \\
Overdraft & 1,727 & 502 & 2,045 & 609 & 474 & 81 \\
\hline Gross Financial Wealth & 17,401 & 3,174 & 18,443 & 3,012 & 13,289 & 3,816 \\
Net Financial Wealth & 10,751 & 2,290 & 10,456 & 1,994 & 11,915 & 3,455 \\
\hline
\end{tabular}

Mean and median include individuals owning the respective asset.

Table 5: Utilization Rates in Comparison to Survey Data

Total Risky Assets External Risky Assets Internal Risky Assets

\begin{tabular}{|c|c|c|c|c|c|c|c|}
\hline Article & Survey & Survey data & Bank data & Survey data & Bank data & Survey data & Bank data \\
\hline Börsch-Supan and Eymann (2002) & EVS & 25.1 & 19.24 & 10.0 & 10.52 & 12.9 & 11.92 \\
\hline Börsch-Supan et al. (2009) & SAVE & 19.6 & 19.01 & - & 10.34 & - & 11.81 \\
\hline Guiso, Haliassos and Jappelli (2003) & EVS & 18.9 & 19.24 & 10.0 & 10.52 & - & 11.92 \\
\hline Guiso, Sapienza and Zingales (2008) & SHARE & 22.9 & 22.77 & 14.0 & 15.05 & - & 11.80 \\
\hline Christelis, Georgarakos and Haliassos (2013) & SHARE & 25.4 & 22.77 & - & 15.05 & - & 11.80 \\
\hline
\end{tabular}


The study by Börsch-Supan and Eymann (2002) and the one by Guiso, Haliassos and Jappelli (2003) make use of the Survey of Income and Expenditure (EVS). ${ }^{16}$ This survey excludes households with an income of more than $18,000 €$ per month. Börsch-Supan et al. (2009) employ the SAVE survey (Sparen und Altersvorsorge in Deutschland). ${ }^{17}$ The SAVE survey includes all heads of households in the age of 16 or older. The studies by Guiso, Sapienza and Zingales (2008) and Christelis, Georgarakos and Haliassos (2013) make use of the Survey of Health Ageing and Retirement in Europe (SHARE), which includes only heads of households in the age of 50 years and more. Interestingly enough, our dataset reproduces many of the findings of the reported studies.

Our descriptive analysis allows us drawing several conclusions. First, the stockholding puzzle seems not to be an artifact of survey research. Even when using real world bank data, only a comparatively small fraction of all bank customers hold risky assets. Second, while the percentage of bank customers holding some sort of risky asset in his or her portfolio is similar in East and West Germany, the composition of risky assets seems to differ. While East German savings bank customers more often hold mutual funds, managed by their own bank in their portfolios, West German customers more often hold external mutual funds, stocks and bonds. West Germans also tend to hold much more of their wealth in risky external assets. However, the samples of West and East German customers strongly differ in some of their properties. The West German bank customers exhibit higher gross wealth and lower net wealth than their East German counterparts. Moreover, on average West German bank customers are younger than East German savings bank customers. Thus, a purely descriptive analysis is incapable of answering the question whether the observed differences in investment behaviour are driven by different sample characteristics or in fact by differing preferences. In order to answer this question we proceed with a more advanced empirical analysis.

\subsection{Estimation Strategy and Applied Sampling Procedure}

The aim of the following empirical analysis is to uncover whether customers from East German savings banks differ systematically from those of West German banks as a consequence of their different informal institutional background. As pointed out by Miniaci and Weber (2002) the extensive and intensive portfolio decision should be distinguished as the decision to hold risky assets at all might substantially differ from the one how much of these assets should be held. Our estimation strategy therefore consists of two steps. In a first step (Section 4) we study the decision to hold risky assets at the extensive margin. We thereby distinguish between the decision to hold any type of risky asset, risky external assets and risky internal assets (DEKA fonds). As the explanatory variables are binary in these cases, we employ logit estimation approaches for this purpose. We then (Section 5) turn to the analysis of the decision to hold risky assets at the intensive margin. Thus, our explanatory variable is the absolute amount of risky assets, an individual holds. ${ }^{18}$ Since we deal with heavily censored variables and we are likely to be confronted with non-linearities we apply a censored quantile-regression approach to the data.

\footnotetext{
${ }^{16}$ For a detailed description of the survey see e.g. Becker et al. (2003).

${ }^{17}$ See Schunk (2007) for a more detailed description of the SAVE survey.

${ }^{18}$ We refrain from studying the share of assets which is held in risky assets as explanatory variable as our dataset likely gives no complete account of bank customers' wealth.
} 
As explained earlier, our raw data consists of the portfolios of customers of eleven German savings banks. Eight of them are located in East Germany while three operate in West Germany. The joint customer sample is thus strongly biased towards East German customers. In order to construct an appropriate and computationally convenient dataset we proceeded as follows: We first selected all customers of the West German savings bank. We then randomly picked customers of the eight East German savings banks and added them to the dataset until the share of East German customers in the newly constructed dataset equals the East German population share. Following this procedure we end up with a dataset consisting of 430,177 bank customers. This dataset is used for the following empirical analysis.

\section{The Decision to Hold Risky Assets at the Extensive Margin}

In order to study the decision to hold risky assets at the extensive margin we proceed in two steps. In the first step we study the factors determining the decision to hold risky assets within a logistic regression approach without distinguishing between East and West German customers and thus neglecting possibly existing institutional factors as explanatory variables. In a second step we add a dummy variable for East German savings bank customers to the regression approach.

\subsection{Baseline Regression Results}

In our baseline regression approach we aim at identifying factors determining savings bank customers' decision to hold risky assets. In order to do so we construct three additional dummy variables for the ownership of risky assets. The first two dummies indicate whether a bank customer $i$ holds risky assets in the form of DEKA funds

$$
\text { Own }(\text { Risky int })_{i}=\left\{\begin{array}{lll}
1 & : & \text { Risky int }>0 \\
0 & : & \text { else }
\end{array}\right.
$$

or in the form of external risky assets

$$
\text { Own }(\text { Risky ext })_{i}=\left\{\begin{array}{lll}
1 & : & \text { Risky ext }>0 \\
0 & : & \text { else }
\end{array}\right.
$$

Moreover, we construct a dummy variable for owners of any type of the two risky asset classes

$$
\text { Own }(\text { Risky })_{i}=\left\{\begin{array}{lll}
1 & : \text { Risky ext }>0 \text { and } / \text { or Riskyint }>0 \\
0 & : \text { else }
\end{array}\right.
$$

We then regress each of these dummy variables on a number of explanatory variables within a logit estimation approach and estimate the model with Maximum Likelihood techniques. The choice of the explanatory variables follows the earlier summarized literature and data availability. First, we control for a bank customer's gross financial wealth by creating quartile dummies. Second, we include a dummy for having any sort of liability. Third, we add a dummy variable for male customers to the set of explanatory variables. Fourth, we control for the employment status with a dummy for the receivers of social transfer payments. Fifth, we add a dummy for customers of banks located in urban 
regions. And sixth, we control for a customer's age. The large number of available observations allows us employing the earlier mentioned dummy approach. ${ }^{19}$

As reference category we use the median customer, which is a female 50 years old customer in the second financial gross wealth quartile in an urban environment. Moreover, the reference customer does not hold any liabilities and does not receive social transfers.

The estimation results for the baseline regression are summarized in Table 6. Columns (1) and (2) report the results for the ownership of any type of risky asset. Column (1) displays the estimated coefficients, standard errors and significance levels. In order to be able to judge the strength of the estimated effects we report the referring marginal effects in column (2). ${ }^{20}$

As expected, we find gross financial wealth to increase the likelihood to hold risky assets. The effect of financial wealth is comparatively strong, as an increase in gross financial wealth from the second to the third quartile increases the probability to hold risky assets by 8.1 percentage points. An increase to the highest quartile raises the likelihood to hold risky assets by 17.1 percentage points. The likelihood to hold risky assets also increases if the customer has any liabilities. However, the effect is much weaker. Switching the liabilities dummy to one raises the probability to hold risky assets by 3.8 percentage points. Male bank customers exhibit a higher probability to hold risky assets than their female counterparts. However, the probability to hold risky assets is only slightly higher (1.2 percentage points). Customers receiving social transfers have a lower likelihood to hold risky assets (-7.2 percentage points). Customers of rural savings banks also have a lower probability to hold risky assets, however, the difference to urban customers is not large (-0.9 percentage points). In the upper part of Figure 1 we show a graphical visualization of the marginal age effects. The dots show the estimated marginal effects of the different age classes (relative to a customer in the age of 50). Obviously, the age effects follow an inverse u-shaped pattern (which can well be approximated by the displayed polynomial function, see the lower part of Figure 1). Nagelkerke's Pseudo R-Square measure indicates that the set of control variables explains $15 \%$ of the observed variation in risky asset ownership.

When comparing our estimation results for the set of employed control variables to those found in the previous empirical literature, either based on administrative (Calvet, Campbell and Sodini, 2006) or survey data (e.g. Guiso, Sapienza and Zingales, 2008), our results turn out to be qualitatively similar. All cited studies find significantly positive effects of gross financial wealth on the probability to hold risky assets. In our list the only study controlling for total liabilities by Calvet, Campbell and Sodini (2007) finds the same positive relationship with risky asset ownership as we did. The study by Guiso et al. (2008) is one example for gender controls in a stock market participation context. They find male bank customers to exhibit higher probabilities to hold risky assets, a result which again coincides with our findings. With the exception of the study by Christelis, Georgarakos and Haliassos (2013) the existing empirical studies report a negative relationship between age and asset ownership. While we find an inverse u-shaped

\footnotetext{
${ }^{19}$ As discussed earlier, we thus implicitly assume cohort effects to be zero, see Campbell (2006) and Heaton and Lucas (2000).

${ }^{20}$ Since the marginal effects themselves depend on the level of the variables, we calculate the marginal effects at the earlier described median individual and vary the dummy variables from zero to one.
} 
Table 6: Estimation Results Baseline Logit Regression

Total Risky Assets External Risky Assets Internal Risky Assets
(1)
(2)
(3)
(4)
(5)
(6)

\begin{tabular}{|c|c|c|c|c|c|c|}
\hline Variable & Coeff. & Effect & Coeff. & Effect & Coeff. & Effect \\
\hline \multirow[t]{2}{*}{ Constant } & $-1.769 * * *$ & & $-2.797 * * *$ & & $-2.318 * * *$ & \\
\hline & $(0.032)$ & & $(0.042)$ & & $(0.036)$ & \\
\hline \multirow[t]{2}{*}{ Q1 Gross financial wealth } & $-0.894 * * *$ & -0.111 & $-0.938 * * *$ & -0.051 & $-0.881 * * *$ & -0.072 \\
\hline & $(0.016)$ & & $(0.028)$ & & $(0.019)$ & \\
\hline \multirow[t]{2}{*}{ Q3 Gross financial wealth } & $0.649 * * *$ & 0.081 & $0.909 * * *$ & 0.049 & $0.570 * * *$ & 0.046 \\
\hline & $(0.012)$ & & $(0.018)$ & & $(0.014)$ & \\
\hline \multirow[t]{2}{*}{ Q4 Gross financial wealth } & $1.372 * * *$ & 0.171 & $1.869 * * *$ & 0.101 & $1.274 * * *$ & 0.104 \\
\hline & $(0.012)$ & & $(0.017)$ & & $(0.014)$ & \\
\hline \multirow[t]{2}{*}{ Total Liabilities } & $0.309 * * *$ & 0.038 & $0.240 * * *$ & 0.013 & $0.286 * * *$ & 0.023 \\
\hline & $(0.010)$ & & $(0.013)$ & & $(0.012)$ & \\
\hline \multirow[t]{2}{*}{ Male } & $0.095 * * *$ & 0.012 & $0.120 * * *$ & 0.006 & $0.081 * * *$ & 0.007 \\
\hline & $(0.008)$ & & $(0.011)$ & & $(0.010)$ & \\
\hline \multirow[t]{2}{*}{ Transfer } & $-0.575^{* * *}$ & -0.072 & $-0.686 * * *$ & -0.037 & $-0.474 * * *$ & -0.039 \\
\hline & $(0.030)$ & & $(0.051)$ & & $(0.033)$ & \\
\hline \multirow[t]{2}{*}{ Rural } & $-0.075^{* * *}$ & -0.009 & $-0.493 * * *$ & -0.027 & $0.276 * * *$ & 0.023 \\
\hline & $(0.009)$ & & $(0.012)$ & & $(0.011)$ & \\
\hline AIC & 379614 & & 245697 & & 288613 & \\
\hline Pseudo R-Squared & 0.150 & & 0.200 & & 0.116 & \\
\hline LR-Test (p.) & 0.00 & & 0.00 & & 0.00 & \\
\hline Observations & 430177 & & 430177 & & 430177 & \\
\hline
\end{tabular}

Standard errors are reported in brackets. The table omits the coefficients of the age dummies. Reported marginal effects belong to a female individual in the median age of 50, affiliated with an urban savings bank, belonging into the second gross wealth quantile and receiving no transfer income.

The marginal effects belong to a switch in the referring dummy variable from zero to one

Significance levels: "*” indicates significance on the 90\%-, "**" on the 95\%- and "***" on the 99\%-confidence level. 

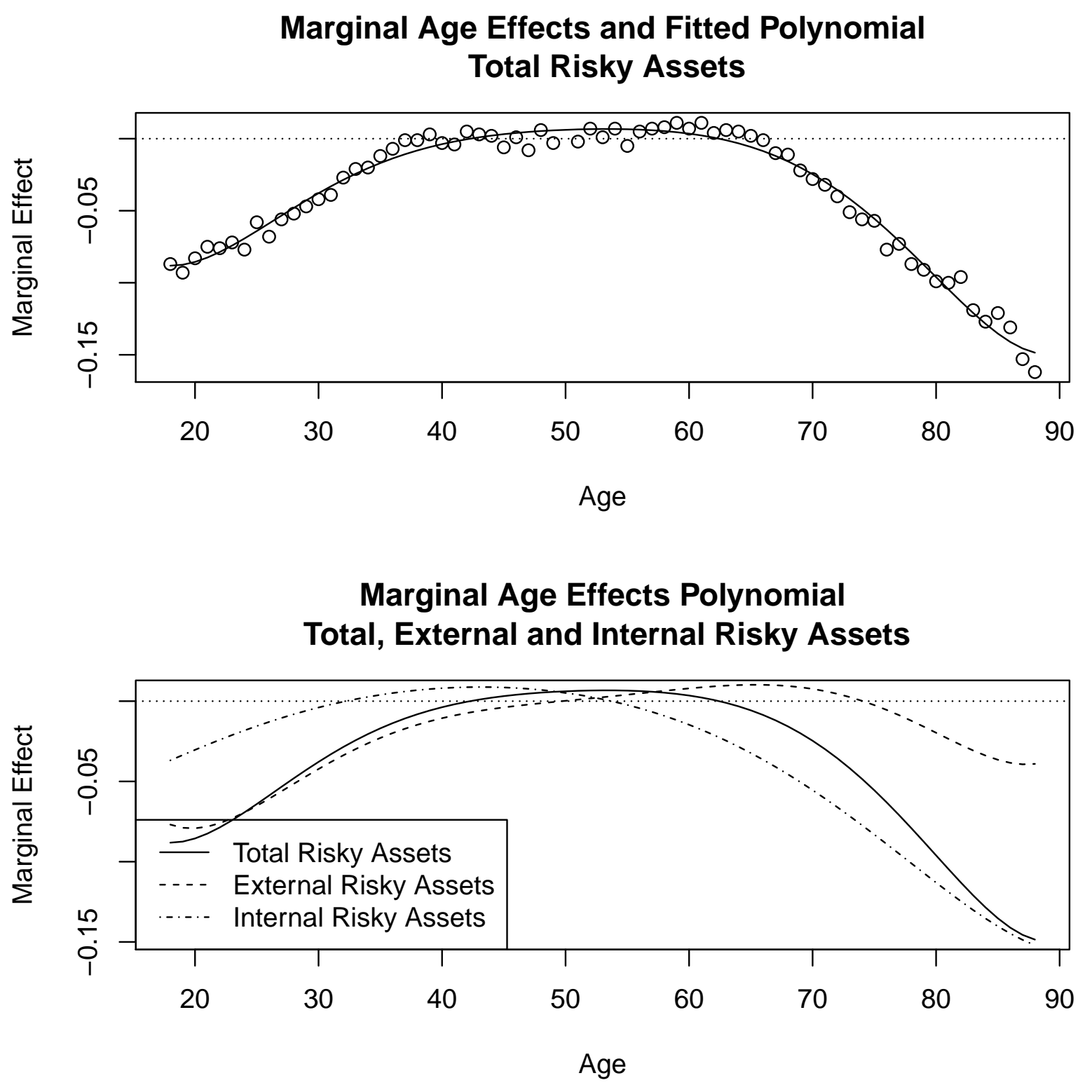

Figure 1: Marginal Age Effects in Baseline Regression 
Table 7: Comparison with Results in the Related Literature

\begin{tabular}{|c|c|c|c|c|}
\hline & Gross Financial Wealth & Total Liabilities & Male & Age \\
\hline Calvet, Campbell and Sodini (2007) & + & + & & - \\
\hline Börsch-Supan and Eymann (2002) & + & & & - \\
\hline Guiso, Sapienza and Zingales (2008) & + & & + & - \\
\hline Christelis, Georgarakos and Haliassos (2013) & + & & & + \\
\hline
\end{tabular}

relationship, this finding is again broadly in line with the existing literature..$^{21}$

When repeating the estimation for the two earlier described subclasses of risky assets (external and internal risky assets) the qualitative results remain similar (see columns (3) to (6) in Table 6). All control variables have the same sign. The entire set of controls remains significant on the $99 \%$-level. However, as many individuals only hold one class of risky assets, the marginal effects are in general considerably smaller for both asset classes. Moreover, internal risky assets do react much stronger to changes in the control variables than external risky assets. As an example, an increase in gross financial wealth, as measured by moving from the second to the fourth quartile, increases the probability to hold internal risky assets by 13.0 percentage points while the probability to hold external risky assets only increases by 6.5 percentage points. There are also considerable differences in the age profiles of risky internal and risky external assets. In the lower part of Figure 1 we show the age patterns from the three different estimations as smoothed polynomials. While the age pattern for internal risky assets is similar to the one resulting from estimating the determinants of total risky assets, the polynomial for external risky assets is much more flattened. Thus, the decision to hold external risky assets is much less related to age than the one to hold internal risky assets. The shift of the urban coefficient sign indicates a location-specific asset distribution. A customer in an rural area has a decreased likelihood to hold external risky assets, whereas his probability to hold internal risky assets is increased by a comparable amount (external -2.7 vs. 2.3 percentage points).

\subsection{Inclusion of an Institutional Dummy}

In the previous subsection we treated the Germans as a homogenous population. However, as discussed earlier, at least the elderly East Germans have lived under completely different institutions than the West Germans for almost 40 years. It is thus interesting to study whether the differences in institutions have left their traces in bank customers' portfolio behaviour. In order to study this question we distinguish in the following between customers from East and from West German savings banks.

Somewhat problematic, we have no information on the place of birth of bank customers and we also do not know in which part of the two Germanies the customers have been living throughout the period of German division. We thus cannot rule out that a significant share of East German bank customers are originally from West Germany and

\footnotetext{
${ }^{21}$ The effect of receiving transfer income and being affiliated with an urban savings bank has yet not been studied explicitly.
} 
have moved to East Germany (and the other way round). Moreover, the younger bank customers have lived under the same institutional circumstances in reunified Germany. While it is well possible that their portfolio behaviour is shaped or at least influenced by the experiences of their families and friends, which they collected in the earlier existing systems, one might nevertheless expect that the own experiences made under the institutions in reunified Germany nowadays play the predominant role. Thus, even when the formerly different institutions in the two parts of Germany had an influence on portfolio behavior it might be hard to disentangle them in our data. However, when we in fact find differences in between East and West German bank customers this might be interpreted as a very strong indication for the existence, the strength and the persistence of these effects.

The estimation results derived under the inclusion of an institutional dummy variable for East German bank customers are summarized in Table 8. Columns (1) and (2) again report the results of a logit regression explaining individual ownership of (any sort of) risky assets. Column (1) displays the estimated coefficients, standard errors and significance levels. Column (2) reports the referring marginal effects. The estimated coefficients for the control variables from the baseline regression remain broadly unaffected in sign and magnitude. The coefficient of the variable of central interest, the East dummy, turns out to be positive and is highly significant. Thus, savings bank customers in East Germany tend to have a slightly higher probability of holding some sort of risky assets than their West German counterparts. However, the effect turns out to be comparatively small in size as the marginal effect amounts to only 0.7 percentage points. Nevertheless, the inclusion of the East dummy tends to improve the fit as the lower AIC value indicates.

Interestingly enough, we find slightly more pronounced effects when studying the two types of risky assets separately. In columns (3) and (4) we report the estimation results for external risky assets. East Germans tend to hold less external risky assets than their West German counterparts. According to the calculated marginal effect, West Germans have a 2.2 percentage points higher probability to hold external risky assets than East Germans. While this effect is not large in size, it is not negligible as on average only $11 \%$ of all Germans hold this type of risky asset in their portfolios (see Table 2). As column (5) and (6) indicate, East Germans are more likely holding risky internal assets in their portfolios. Again, the estimated coefficient is highly significant and delivers a marginal effect of 2.9 percentage points. As only $12 \%$ of all Germans hold risky internal assets this marginal effect is again not negligible.

Altogether, our empirical analysis of the decision to hold risky assets at the extensive margin is broadly in line with the findings of the earlier presented descriptive analysis of utilization rates. While we find no substantial effect of institutions on the decision to hold any type of risky asset, institutions tend to play a role in the decision which assets are held. While West Germans have a higher probability to hold externally managed fonds or to buy risky assets themselves, East Germans are favouring fonds managed by their savings bank. However, the differences between East and West Germans are not large, a finding which is broadly in line with the results reported in Fuchs-Schündeln and Haliassos (2013). In the next section we study whether this finding translates to the intensive margin of the decision to hold risky assets. 
Table 8: Estimation Results Logit Regression with Institutional Dummy

Total Risky Assets External Risky Assets Internal Risky Assets
(1)
(2)
(3)
(4)
(5)
(6)

\begin{tabular}{|c|c|c|c|c|c|c|}
\hline Variable & Coeff. & Effect & Coeff. & Effect & Coeff. & Effect \\
\hline \multirow[t]{2}{*}{ Constant } & $-1.781 * * *$ & & $-2.732 * * *$ & & $-2.402 * * *$ & \\
\hline & $(0.032)$ & & $(0.042)$ & & $(0.036)$ & \\
\hline \multirow[t]{2}{*}{ Q1 Gross financial wealth } & $-0.892 * * *$ & -0.110 & $-0.951 * * *$ & -0.055 & $-0.870 * * *$ & -0.066 \\
\hline & $(0.016)$ & & $(0.028)$ & & $(0.019)$ & \\
\hline \multirow[t]{2}{*}{ Q3 Gross financial wealth } & $0.649 * * *$ & 0.080 & $0.913 * * *$ & 0.052 & $0.571 * * *$ & 0.043 \\
\hline & $(0.012)$ & & $(0.018)$ & & $(0.014)$ & \\
\hline \multirow[t]{2}{*}{ Q4 Gross financial wealth } & $1.373^{* * *}$ & 0.169 & $1.873 * * *$ & 0.107 & $1.292 * * *$ & 0.098 \\
\hline & $(0.012)$ & & $(0.017)$ & & $(0.014)$ & \\
\hline \multirow[t]{2}{*}{ Total Liabilities } & $0.312 * * *$ & 0.038 & $0.217 * * *$ & 0.012 & $0.304 * * *$ & 0.023 \\
\hline & $(0.010)$ & & $(0.013)$ & & $(0.012)$ & \\
\hline \multirow[t]{2}{*}{ Male } & $0.096^{* * *}$ & 0.012 & $0.112 * * *$ & 0.006 & $0.089 * * *$ & 0.007 \\
\hline & $(0.008)$ & & $(0.011)$ & & $(0.010)$ & \\
\hline \multirow[t]{2}{*}{ Transfer } & $-0.598 * * *$ & -0.074 & $-0.521 * * *$ & -0.03 & $-0.614 * * *$ & -0.047 \\
\hline & $(0.030)$ & & $(0.052)$ & & $(0.033)$ & \\
\hline \multirow[t]{2}{*}{ Rural } & $-0.078 * * *$ & -0.010 & $-0.480 * * *$ & -0.028 & $0.256 * * *$ & 0.019 \\
\hline & $(0.009)$ & & $(0.012)$ & & $(0.011)$ & \\
\hline \multirow[t]{2}{*}{ East } & $0.057 * * *$ & 0.007 & $-0.388 * * *$ & -0.022 & $0.384 * * *$ & 0.029 \\
\hline & $(0.010)$ & & $(0.014)$ & & $(0.012)$ & \\
\hline AIC & 379585 & & 244916 & & 287577 & \\
\hline Pseudo R-Squared & 0.151 & & 0.204 & & 0.120 & \\
\hline LR-Test（p.) & 0.00 & & 0.00 & & 0.00 & \\
\hline Observations & 430177 & & 430177 & & 430177 & \\
\hline
\end{tabular}

Standard errors are reported in brackets. The table omits the coefficients of the age dummies. Reported marginal effects belong to a female individual in the median age of 50, affiliated with an urban savings bank, belonging into the second gross wealth quantile and receiving no transfer income.

The marginal effects belong to a switch in the referring dummy variable from zero to one

Significance levels: "*” indicates significance on the 90\%-, "**” on the 95\%-and "***" on the 99\%-confidence level. 


\section{The Decision to Hold Risky Assets at the Intensive Margin}

There are two basic strategies to study the intensive margin of the decision to hold risky assets: (i) the analysis of shares of certain assets in (total or financial) wealth and (ii) the analysis of absolute asset holdings. Most of the existing literature focuses on asset shares. ${ }^{22}$ A central finding of this literature is that risky asset shares in general tend to increase in wealth. However, conditional on participation cross-section evidence reports a relatively small impact of wealth (Guiso, Haliassos and Jappelli, 2003). ${ }^{23}$ Due to the fact that we base our empirical analysis on bank account data, our picture on individual wealth is likely incomplete. We therefore refrain from studying asset shares but turn to an analysis of the absolute levels of risky asset holdings.

The empirical literature concerned with studying absolute asset levels is comparatively small. A major issue in this literature is to deal adequately with likely occurring non-linearities. Typically this problem is tackled by applying semi-parametric estimation techniques. Christelis, Georgarakos and Haliassos (2013) use quantile regression methods to decompose differences of asset level distributions across countries. They show that country differences, opposed to population characteristics, largely explain asset holding differences. Bilias, Haliassios and Georgarakos (2013) apply the same method to analyze whether an increased participation in stock markets leads to a more equal distribution of wealth ("equity culture") but fail to find supporting evidence for this hypothesis.

A major obstacle of the application of quantile regression is the large number of individuals not holding risky assets at all. In order to account for this problem, Miniaci and Weber (2002) propose to use censored quantile regressions. ${ }^{24}$ In our subsequent analysis of the intensive decision to hold risky assets, we follow this advice.

\subsection{The Censored Quantile Regression Method and its Implementation}

Parametric models as e.g. ordinary least square estimations capture the effect on the conditional mean of a dependent variable. However, this comes at the price of failing to capture the effects in different parts of the conditional distribution. As we are interested in asset levels, we deal with asymmetrically distributed variables with potentially influential outliers. If these properties translate into the error term, they violate the distributional assumptions of ordinary least square estimations. Moreover, the conditional mean is not representative for an asymmetric distribution with a fat tail. Intuitively, it seems plausible that individuals with a high level of asset holdings react differently on changes in the control variables than their counterparts holding less of the referring asset. An adequate solution to estimate the effect on the entire distribution and to deal with heterogeneity and outliers is to employ quantile regressions.

The pioneering work of Koenker and Bassett (1978) incorporates a linear model into the minimization of the sum of absolute deviations. The latter can be used to calculate sample quantiles

\footnotetext{
${ }^{22}$ See e.g. King and Leape (1998), Bertaut and Starr-McCluerr (2002), Vissing-Jorgensen (2002), Ameriks and Zeldes (2004), Guiso, Sapienza and Zingales (2004), Cocco (2005), Calvet, Campbell and Sodini (2007) or Nagel and Malmendier (2011).

${ }^{23}$ Brunnermeier and Nagel (2008) show that a positive change in wealth does not imply a positive change in the risky asset share. Despite their slightly negative wealth change coefficient their estimates favor constant relative risk aversion models (CRRA).

${ }^{24}$ For applications of this method in the household finance context see Hochguertel (2003) and Guiso, Jappelli and Terlizzese (1996).
} 


$$
\begin{gathered}
Q_{\tau}\left(y_{i} \mid x_{i}\right)=x_{i}^{\prime} \beta_{\tau}+e_{i} \\
i=1, \ldots, n \\
\tau=(0,100)
\end{gathered}
$$

According to equation 4 the parameter vector $\beta$ is estimated separately for each conditional quantile. The idea behind this approach is based on a cross-section with $n$ observations and the quantiles of interest $(\tau)$ being in between 0 and $100 .{ }^{25}$ The minimization procedure concerns the piecewise linear absolute value function

$$
\min _{\beta} \frac{1}{N}\left\{\Sigma_{y_{i} \geq x_{i}^{\prime} \beta_{\tau}} \tau\left|y_{i}-x_{i}^{\prime} \beta_{\tau}\right|+\Sigma_{y_{i}<x_{i}^{\prime} \beta_{\tau}}(1-\tau)\left|y_{i}-x_{i}^{\prime} \beta_{\tau}\right|\right\}
$$

which can be solved via linear programming (Koenker and Hallock, 2001). ${ }^{26}$ The technique does not assume any specific error distribution. Furthermore, conditional quantiles are less prone to be affected by outliers.

As a consequence of the stockholding puzzle, our data on risky asset levels is heavily censored at zero. Powell $(1984,1986)$ proposes a robust way of dealing with censoring in the quantile regression context. He extends the standard quantile regression approach to the non-negative dependent variable case. The approach is again independent of the concrete error distribution. In order to obtain a unique solution, some weaker requirements have to be fulfilled. The regressors have to be non-collinear. Moreover, the conditional regression quantiles to be estimated have to contain a fraction of non-censored observations with sufficient informative variation. As Powell (1984) points out, large samples and at least the upper quantiles should meet these criteria. ${ }^{27}$ The case of left-censored data is given by

$$
Q_{\tau}\left(y_{i} \mid x_{i}\right)=\max \left\{x_{i}^{\prime} \beta_{\tau}+e_{i}, 0\right\}
$$

The maximum takes either the censored value of zero or a non-censored value. The remaining general formulation of equation 4 is identical.

The application of the method includes the highly complex computation of non-differentiable and non-convex distance functions (Fitzenberger and Winkler, 2007). In this context multiple local optima can occur. As Fitzenberger (1997) points out, most of these algorithms perform quite poorly for high degrees of censoring. In order to deal with our high degree of censoring and the high data dimensionality, we use the three-step censored quantile regression approach proposed by Chernozhukov and Hong (2002). It is computationally less complex as the necessary steps include a parametric regression and the minimization problems to be solved are convex.

\footnotetext{
${ }^{25}$ It is important to stress that the regression quantile is conditional on the underlying model and not equal to the quantile of the left hand variable.

${ }^{26}$ For an overview on quantile regression algorithms and computational efficiency, see Fitzenberger (1997).

${ }^{27}$ Powell $(1984,1986)$ also shows under which circumstances the estimator is consistent and asymptotically normal. The presented method holds for fixed censoring, which is the case in this left-censored framework.
} 
In a first step the censoring probability is estimated parametrically. As we have estimated this probability already in the first step of our analysis we can recur to the referring results. Only observations with a sufficiently small censoring probability are kept in the subsample $J_{0}$. The uncensored subsample is then used in the second step to run a standard quantile regression. The consistent estimates are used to predict the model with the initial complete sample. A new subsample $J_{1}$ contains predictions above the censoring point. It asymptotically selects observations which conditional on the referring independent variables - indicate to be above the censoring threshold. In the third step this subsample is used for an additional standard quantile regression. The now larger set of information increases the efficiency of the estimation. ${ }^{28}$

The presented estimator by Chernozhukov and Hong (2002) is distributionally equivalent to the Powell (1986) approach. This means that the developed inference procedures hold for this method. It should be noted that the underlying probability model makes the model more restrictive, even though the model is allowed to be misspecified. Moreover, it keeps the main features of censored quantile regressions. The presented method has been successfully applied to different issues. Chernozhukov and Hong (2002) analyze the determinants of extramarital affairs, whereas Fack and Landais (2013) used it to study the impact of tax incentives on charitable giving. To the best of our knowledge, it has not been applied to the analysis of household asset levels yet.

In the next section we apply the three-step procedure to our cross-section of risky asset holdings. In the first step, we preserve the (unlikely) censored observations via our previously used logit specification. ${ }^{29}$ The remaining steps follow the described process by Chernozhukov and Hong (2002). Throughout the procedure we use the same set of variables, but we decrease the dimension by approximating gross wealth by its logarithmic value. Furthermore the set of age dummies is replaced with a second order age polynomial. ${ }^{30}$ Due to heavy censoring we concentrate our analysis on the quantiles in between $85 \%$ and $99 \%$. Lower quantiles would induce singularity issues due to a degenerated design matrix. We focus on external and internal risky assets, as total risky assets turned out to mask the effects on the two individual asset classes. ${ }^{31}$

\subsection{Estimation Results}

Due to the non-parametric nature of the applied estimation technique we report the estimation results in diagrams. Each diagram shows the results for one independent variable. On the vertical axis of the diagrams we report the

\footnotetext{
${ }^{28}$ Optionally, step 3 can be repeated in an iterative fashion.

${ }^{29}$ In order to construct a conservative sample we follow Chernozhukov and Hong (2002) and aim at excluding another ten percent of the subsample $J_{0}$. A similar procedure is applied in step 2. However, here the percentage of excluded observations has to be smaller.

${ }^{30}$ Gross wealth is the financial wealth aggregate minus the risky assets under consideration. Due to single observations with a hundred percent holdings of the asset in question we conduct a sinus hyperbolicus transformation. Both representations are common in the literature (see e.g. Christelis, Georgarakos and Haliassos (2013)) and help to avoid matrix singularity for lower quantiles.

${ }^{31}$ Chernozhukov and Hong (2002) suggest the interior point algorithm by Portnoy and Koenker (1997). We use the algorithm provided in the "quantreg" R-package by Koenker (2013). Moreover, we bootstrap the standard errors via 200 replications of the implemented Markov Chain Marginal Bootstrap (MCMB) procedure (He and Mu, 2002). We estimated fifteen quantiles from 85 to 99.
} 
estimated effect for the conditional quantile, the horizontal axis reports the referring conditional quantile. The dark solid curve is the connection of the distinct censored quantile regression estimates. The dashed lines report $95 \%$ confidence intervals which are based on asymptotic normality. In each diagram we also report a parametric benchmark estimate derived from an ordinary least squares estimation.

In a first step we present the estimation results for the intensive margin of the decision to hold risky external assets. The results for the employed control variables are summarized in Figure 2. As all employed control variables exhibit non-linearities, the employed estimation approach seems to be justified and turns out to be superior to the simple OLS estimation, which would lead to a quite different picture. Gross financial wealth increases external risky asset holdings over all reported conditional quantiles. With the exception of the highest quantiles, the effect of financial wealth is increasing in the probability to hold high levels of risky external assets. Customers with liabilities tend to hold higher levels of external risky assets. However, this effect is comparatively small for the lower quantiles. Only for the individuals with very high conditional levels of risky assets, liabilities seem to play a major role. One might speculate this finding to be due to the fact that consumer credits dominate the liabilities in the lower quantiles. These credits are usually not used to finance the purchase of securities. Male customers tend to hold more risky external assets. With the exception of the highest quantiles, where the confidence bands become very large, the gender effect tends to increase over the quantiles. Receivers of transfer income hold significantly less risky external assets. However, the confidence bands turn out to be relatively large. This is due to the fact that receivers of transfer income in general have a low probability to hold risky assets and thus only rarely these observations survive our censoring aproach. ${ }^{32}$ Customers of rural savings banks turn out to hold significantly less external risky assets than their urban counterparts. Moreover, the difference between customers of urban and rural banks strikingly increases in the conditional quantile. Age and age squared have to be interpreted cautiously as the joint effect is not easy to disentangle. Altogether, the results for the control variables turn out to be quite plausible and in general are in line with the existing empirical literature.

The results for the variable of main interest, the institutional dummy, are shown at the bottom of Figure 2. We find that, ceteris paribus, West German savings bank customers hold a higher amount of external risky assets. The effect is significantly negative for all displayed quantiles, although the highest quantile shows somewhat less precision. While the ordinary least squares estimator also delivers a significantly negative coefficient, this coefficient strongly underestimates the results derived by employing the censored quantile regression approach. The customers in the $85 \%$ conditional quantile hold approximately $10,000 €$ more in external risky assets than their East German counterparts. Moreover, the difference between East and West German bank customers strongly increases to more than 35,000€ in the higher conditional quantiles although we explicitly control for gross wealth. Thus, the more likely a customer holds high levels of risky external assets, the more pronounced is the difference between East and West German bank customers. We thus find a strong effect of informal institutions on holdings of external risky assets.

\footnotetext{
${ }^{32}$ It is interesting to note that the least squares estimator would have estimated a counterintuitive positive effect of receiving transfer income.
} 


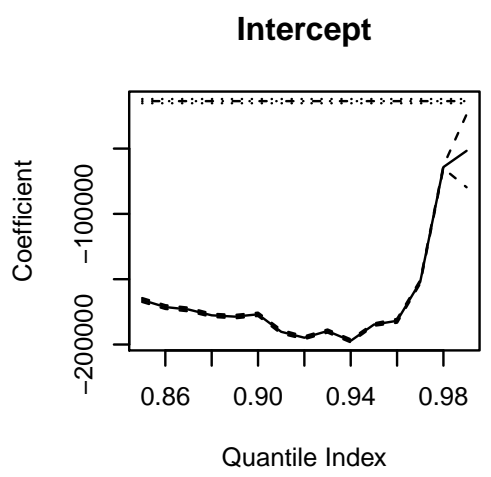

Male

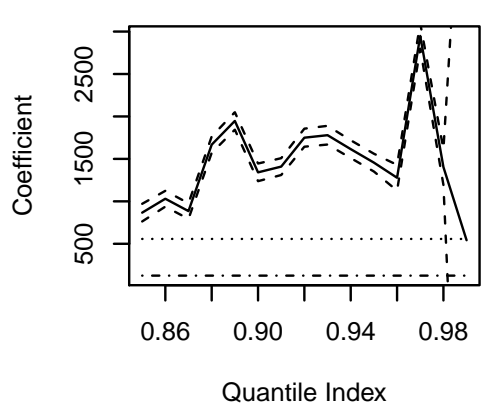

Age

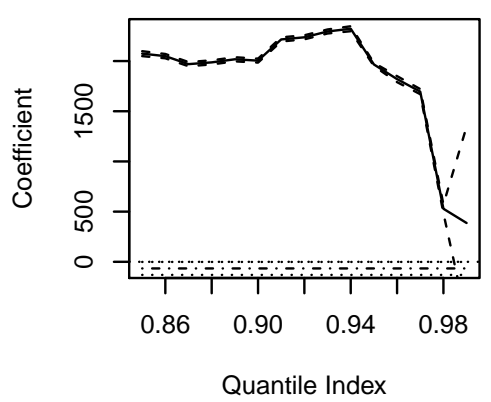

Gross Financial Wealth

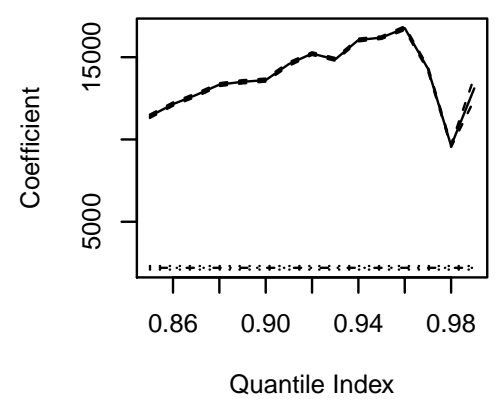

Transfer

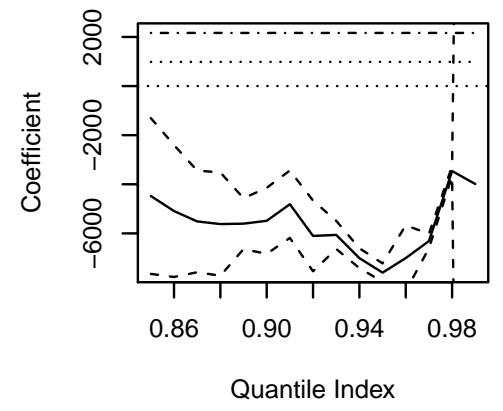

Age Squared

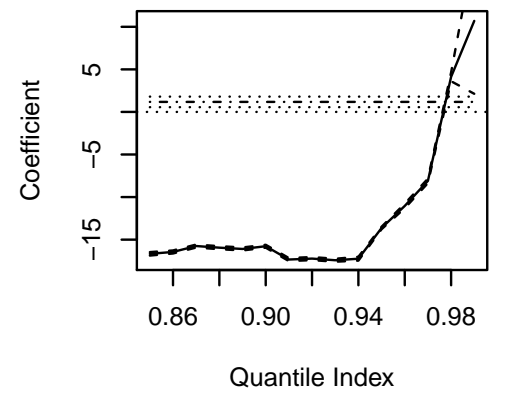

Total Liabilities

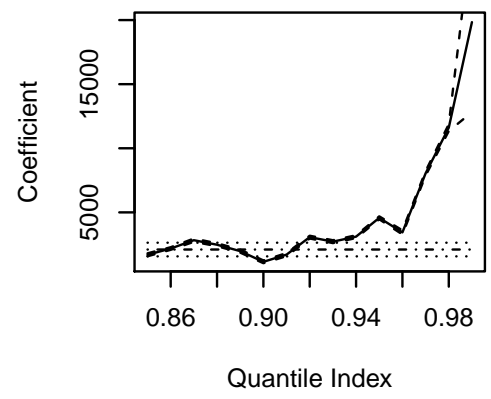

Rural

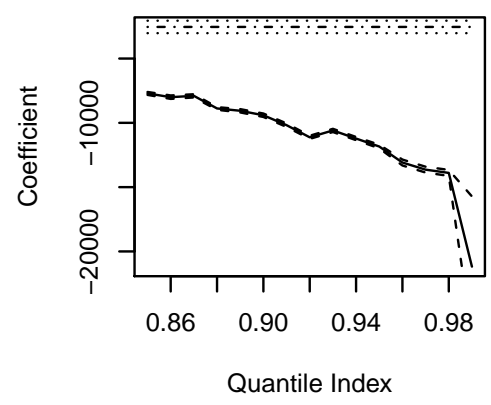

East

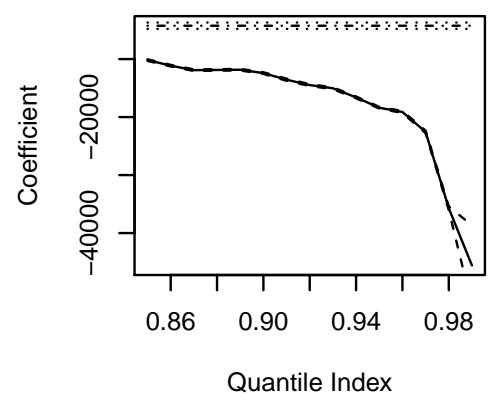

Figure 2: Censored Quantile Regression Results: External Risky Assets 


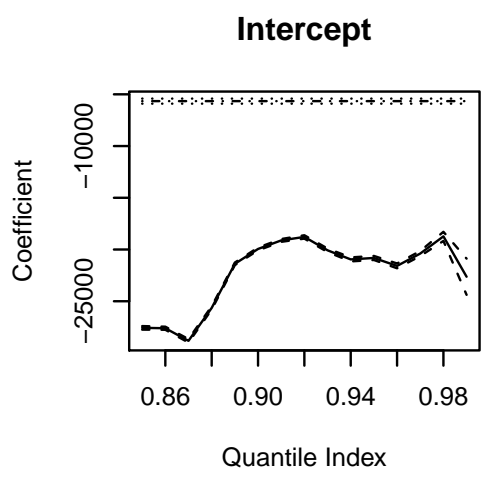

Male

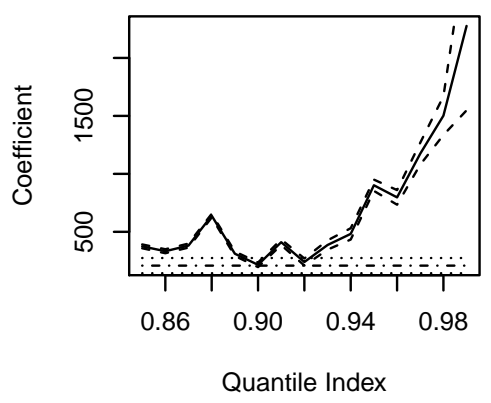

Age

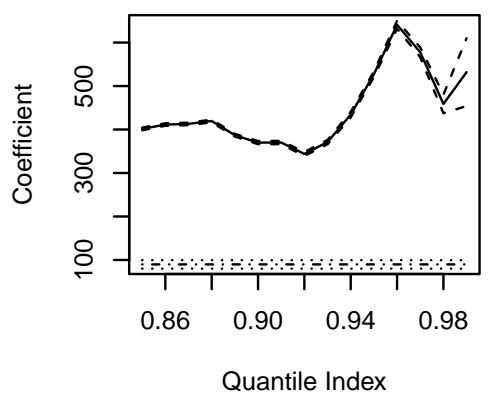

Gross Financial Wealth

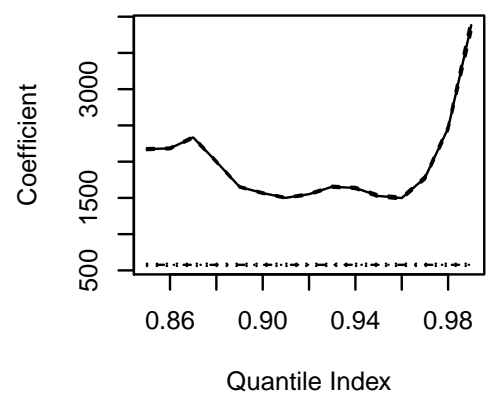

Transfer

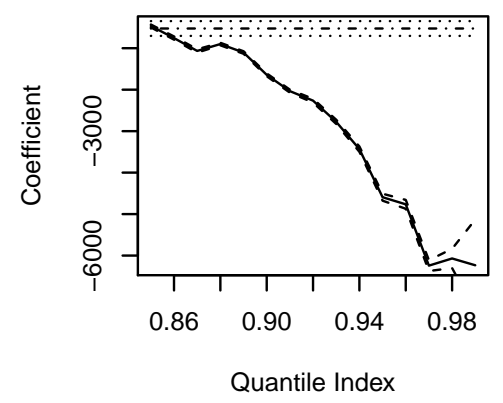

Age Squared

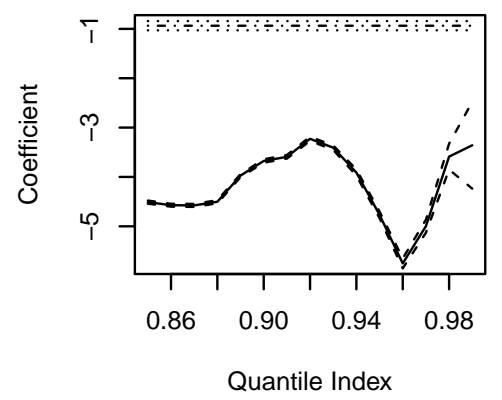

Total Liabilities

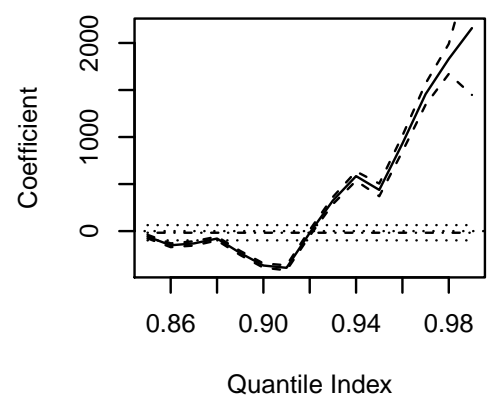

Rural

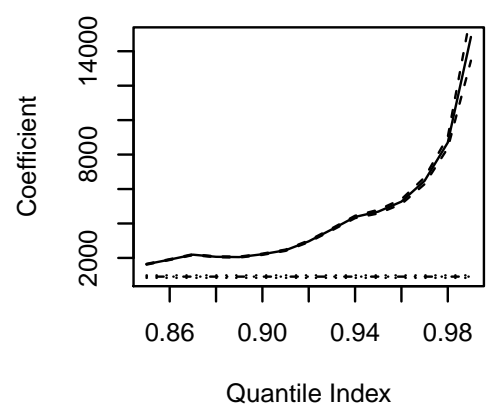

East

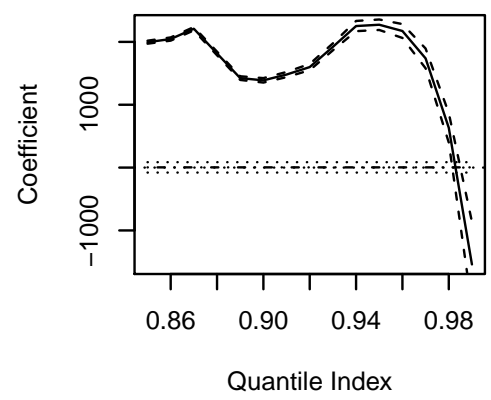

Figure 3: Censored Quantile Regression Results: Internal Risky Assets 
In a second step we present the results for holdings of risky internal assets. Again we start out by visualizing the effects of the control variables (see Figure 3). As in the case of external risky assets we find a plausible positive impact of gross financial wealth, which is comparatively stable in the lower but notably increases in the higher conditional quantiles. Liabilities tend to play a much smaller role for the decision to hold risky internal assets. While the effect of liabilities in the lower conditional quantiles is negative it becomes positive and increases in the higher quantiles. However, the effect is numerically much smaller as in the case of external risky assets. While in the lower conditional quantiles the gender dummy turns out to be unimportant, male bank customers hold significantly more risky internal assets in the higher conditional quantiles. The receivers of transfer income turn out to hold much less risky internal assets. This effect is strongly increasing in the conditional quantile. Being customer of a rural savings bank tends to increase the level of risky internal assets, customers hold. The difference between urban and rural customers further increases in the conditional quantile. For customer age we find a similar but less pronounced effect on asset holdings. Compared to external risky assets, most effects show a much lower degree of uncertainty as measured by the displayed confidence bands. This is especially striking for the highest conditional quantiles. Our set of controls again shows plausible signs.

The bottom of Figure 3 also shows the institutional impact on the level of risky internal asset holdings. While the least squares estimator reports a small and insignificant positive impact of the institutional dummy, the censored quantile regression leads to a different result. Apart from the 99th quantile, which includes customers conditionally holding the highest level of internal risky assets, the impact on holdings is positive and significant. East German bank customers thus tend to hold more internal risky assets than their West German counterparts. However, this effect is comparatively low in size and amounts to roughly $2,000 €$ in those quantiles where the effect is positive.

\section{Learning about institutions}

The earlier presented empirical evidence indicates that informal institutions in East and West Germany more than 15 years after German Reunification still differ and influence the decision to hold risky assets. West Germans have a slightly higher probability to hold external risky assets and hold much higher levels of these assets than their East German counterparts. East Germans exhibit a slightly higher probability to hold risky assets managed by their own savings bank and hold slightly higher volumes of these securities in their portfolios. Thus, while the stockholding puzzle exists in both parts of Germany, in general West Germans tend to play a much more active role in constructing their portfolios. They also tend to be willing to take over more risk, a finding which is in line with the study by Malmendier and Nagel (2011).

In order to understand the consequences of institutional reforms it is also important to understand the process of learning about institutions. The full effect of institutional reforms will typically manifest the earlier, the more quickly the formerly aquired informal institutions fade out. As we only have a cross-section of data we cannot track individual behavior in the course of time. However, we can study whether individuals who had the possibility to 
collect experiences under the former formal institutions differ significantly from those which were too young to do so. By studying this aspect we can shed some light on the question whether informal institutions are passed along to later generations. In their study of U.S. immigrants, Osili and Paulson (2008) find the strongest effects of country-of-origin institutions in the subgroup of immigrants which were in the age of 21 years or older when arriving in the U.S. The effect is still present but somewhat smaller in the group of individuals aged 16 to 20 at the time of immigration. The authors found no effect for the group of immigrants in the age of less than 16 when arriving in the U.S. In order to confirm Osili and Paulson's (2008) results we should find our institutional dummy to play a major role only in the group of bank customers which has been at least 16 (or 21) years old when Germany was reunified.

In order to study this aspect we repeated the analysis of the extensive and the intensive decision to hold risky assets for the same three subgroups of individuals as in Osili and Paulson (2008). The first group consists of people aged at least 21 years at time of German Reunification, the second group includes those aged in between 16 and 20 and the third group covers those which were younger than 16 years old.

Tables 9 and 10 show the estimation results for the decision to hold risky assets at the extensive margin. The tables show the estimation results of separate logit regressions for the three mutually exclusive subsamples of individuals in the age of below sixteen (columns 3 and 4), in between sixteen and twenty (columns 5 and 6) and twenty-one and older (columns 7 and 8) at the time of German Reunification. Columns (1), (3), (5) and (7) contain the estimated logit coefficients, whereas (2),(4), (6) and (8) report the respective marginal effect. We employ the same set of control variables as before but refrain from reporting it in the table due to space restrictions. ${ }^{33}$ The marginal effect is calculated relative to a benchmark individual of the referring group. Thus, median age and the benchmark individual vary over the subsamples.

Table 9 reports the results for external risky assets. The estimated coefficient of the institutional variable turns out to be negative and significant for all three subgroups. Thus, the effect of informal institutions in general turns out to be persistent. However, the marginal effect is almost zero in the group of the individuals which have been below 16 at the time of German Reunification. The effect is slightly larger in the group aged 16 to 20 at the time of German Reunification and turns out to be maximal in the group which has collected their own financial experiences in the time before German Reunification.

Table 10 reports the results for internal risky assets. Again, the effect of the institutional dummy turns out to be positive and significant for all three subsamples. Thus, informal institutions tend to have a persistent effect also for those individuals which have not experienced the former formal institutions. However, again the marginal effects are much more pronounced for the individuals in the age of at least 21 at the time of German Reunification. Compared to the decision to hold external risky assets, the marginal effects are higher but still moderate.

Thus, our findings for the decision to hold risky assets at the extensive margin is broadly in line with the findings of

\footnotetext{
${ }^{33}$ The complete results are available upon request from the authors. With the exception of the gender dummy, the estimated controls are robust with respect to both the sign of the estimated coefficients and the significance levels.
} 
Table 9: Institutional Effect on the Participation Decision for Different Age Groups (External Risky Assets)

$$
\begin{array}{llll}
\text { All } & <16 & 16-20 & >21
\end{array}
$$
(1)
(2)
(3)
(4)
(5)
(6)
(7)

(8)

\begin{tabular}{|c|c|c|c|c|c|c|c|c|}
\hline Variable & Coeff. & Effect & Coeff. & Effect & Coeff. & Effect & Coeff. & Effect \\
\hline \multirow[t]{2}{*}{ East } & $-0.388 * * *$ & -0.022 & $-0.211 * * *$ & -0.001 & $-0.166^{* * *}$ & -0.005 & $-0.406 * * *$ & -0.034 \\
\hline & $(0.014)$ & & $(0.061)$ & & $(0.076)$ & & $(0.015)$ & \\
\hline AIC & 244916 & & 17980 & & 11257 & & 215226 & \\
\hline Pseudo R-Squared & 0.204 & & 0.132 & & 0.135 & & 0.169 & \\
\hline LR-Test (p.) & 0.00 & & 0.00 & & 0.00 & & 0.00 & \\
\hline Observations & 430177 & & 90127 & & 26994 & & 313056 & \\
\hline
\end{tabular}

Standard errors are reported in brackets. The table omits the estimated controls for gross wealth, liabilities, sex, employment,rural environment and age. Reported marginal effects belong to a female individual in the median subsample, age, affiliated with an urban savings bank, belonging into the second gross wealth quantile and receiving no transfer income. The marginal effects belong to a switch in the referring dummy variable from zero to one. Significance levels: "*” indicates significance on the 90\%-, "**" on the 95\%- and "***" on the 99\%-confidence level.

Table 10: Institutional Effect on the Participation Decision for Different Age Groups (Internal Risky Assets)

All $<16$

$16-20$

$>21$

(1)

(2)

(3)

(4)

(5)

(6)

(7)

(8)

\begin{tabular}{lcccccccc} 
Variable & Coeff. & Effect & Coeff. & Effect & Coeff. & Effect & Coeff. & Effect \\
\hline East & $0.384 * * *$ & 0.029 & $0.308 * * *$ & 0.011 & $0.194 * * *$ & 0.012 & $0.409 * * *$ & 0.036 \\
& $(0.012)$ & & $(0.030)$ & & $(0.050)$ & & $(0.013)$ & \\
\hline AIC & 287577 & & 47778 & & 19233 & & 220739 & \\
Pseudo R-Squared & 0.120 & & 0.101 & & 0.118 & & 0.116 & \\
LR-Test (p.) & 0.00 & & 0.00 & 0.00 & & 0.00 & \\
Observations & 430177 & & 90127 & & 26994 & & 313056 & \\
\hline
\end{tabular}

Standard errors are reported in brackets. The table omits the estimated controls for gross wealth, liabilities, sex, employment,rural environment and age. Reported marginal effects belong to a female individual in the median subsample, age, affiliated with an urban savings bank, belonging into the second gross wealth quantile and receiving no transfer income. The marginal effects belong to a switch in the referring dummy variable from zero to one. Significance levels: "*” indicates significance on the 90\%-, "**" on the 95\%- and "***" on the 99\%-confidence level. 
Osili and Paulson (2008). In general, especially those individuals who have experienced the former formal institutions themselves tend to be influenced in their general decision to hold risky assets.

We now turn to the decision to hold risky assets at the intensive margin and repeat the censored quantile regression approach for the three subsamples, thereby employing the same set of control variables as before. As the stockholding puzzle is naturally more pronounced among younger individuals, especially those subsamples containing younger individuals suffer from the highest degree of censoring. As a consequence, we cannot estimate the same amount of quantiles for all three subsamples. Moreover, some of the control variables are themselves correlated with age, such as the e.g. probability to receive social transfers or the likelihood to be very wealthy. This obviously leads to more volatile estimations of the control variables. We therefore focus on the robustness of the institutional dummy and include all possible quantiles. Figure 4 and 5 plot the censored quantile regression coefficients of the institutional dummy.

Figure 4 shows a negative and significant impact of the institutional past on the external risky asset level. The effect is stable for individuals with and without financial experience at reunification. All subgroups have in common that the effect increases for holders who conditionally hold high volumes of risky assets. The group of individuals in the age in between 16 and 20 in the year 1990 shows some distinct characteristics, as the effect is somewhat smaller and decreases less over the quantiles. Nevertheless, even for this group there is a difference of roughly 5,000 and $10,000 €$ in the displayed quantiles. The effect of the oldest subgroup resembles our full sample results. The results show a high precision across all age groups, denoted by the $95 \%$ confidence bands based on the MCMB bootstrapping procedure. Thus, we can conclude that the institutional past has a robust effect on the decision how much external risky assets are held. Different from Osili and Paulson (2008) we find this effect to exist even in the youngest age group which likely made no own financial experiences in the systems before German Reunification.

Figure 4 shows the institutional impact on the holdings of internal risky assets for the three age subsamples. For this asset type the robustness is even more pronounced. Individuals in all three age groups tend to hold more risky assets when being customer of an East German savings bank. Further, across all subsamples the positive effect tends to increase over the quantiles. However, it changes its sign for the highest conditional quantile. Expressed differently, the difference in internal risky asset holdings between East and West German savings bank customers is higher, the more of these assets these subgroups conditionally hold. Interestingly enough, the reversal pattern in the highest 99th quantile, found in our full sample analysis, is also stable across all three subsamples. Opposed to the change of the sign of the institutional impact, here, for the younger individuals (younger than 16 in 1990) the effects turns out to be insignificant.

\section{Conclusions}

Using bank account data from 11 savings banks located in both East and West Germany we studied whether the strong institutional differences between East and West during the time of German division are still visible in portfolio 
East (Age at German Reunification: >21)

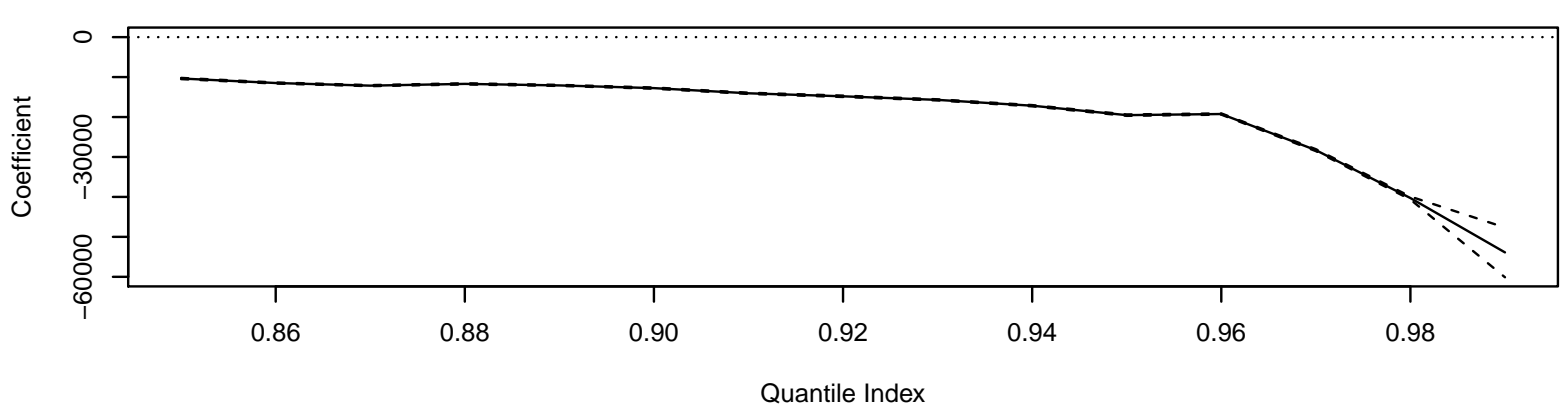

East (Age at German Reunification: 16-20)

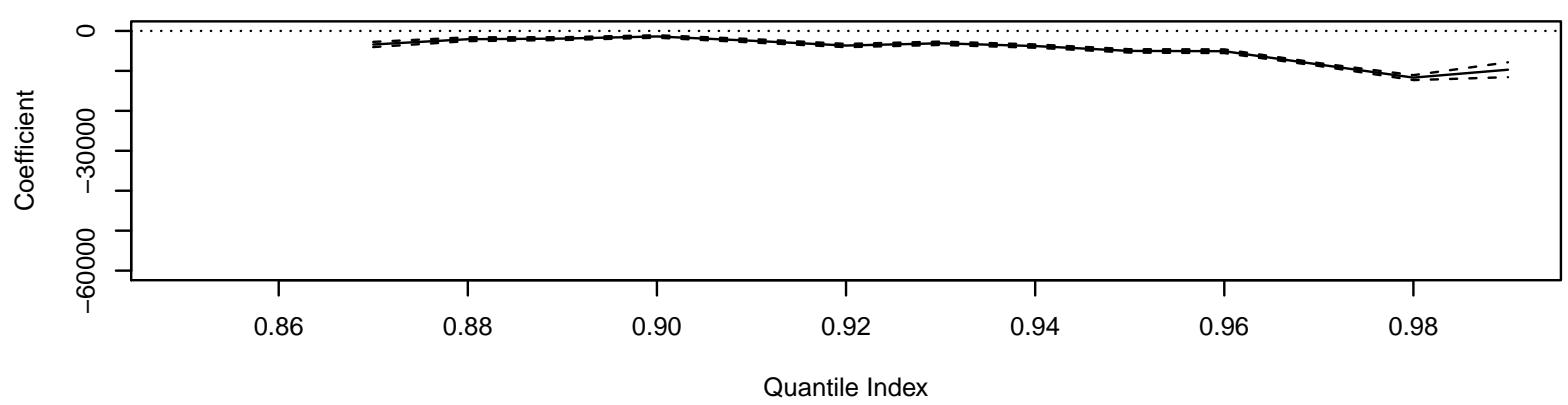

East (Age at German Reunification Age: <16)

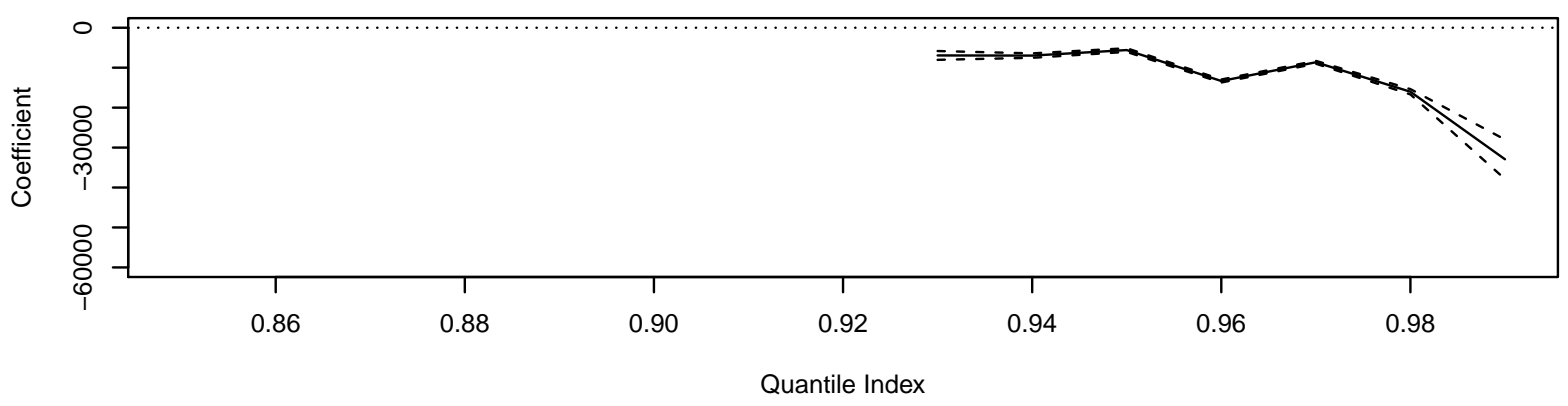

Figure 4: Institutional Impact on Risky External Asset Holding for Different Age Groups 
East (Age at German Reunification: >21)

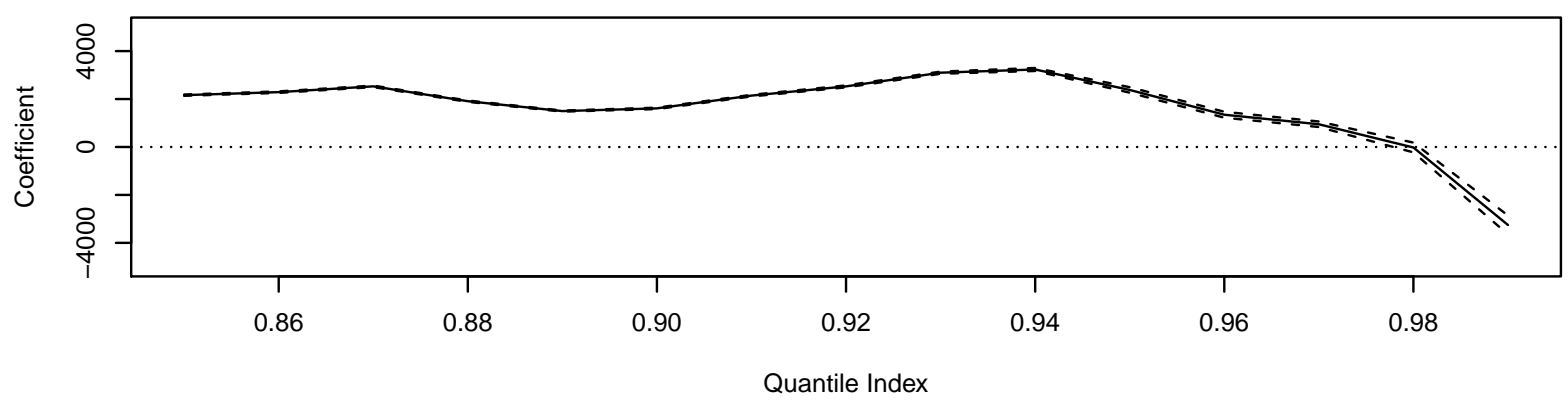

East (Age at German Reunification: 16-20)

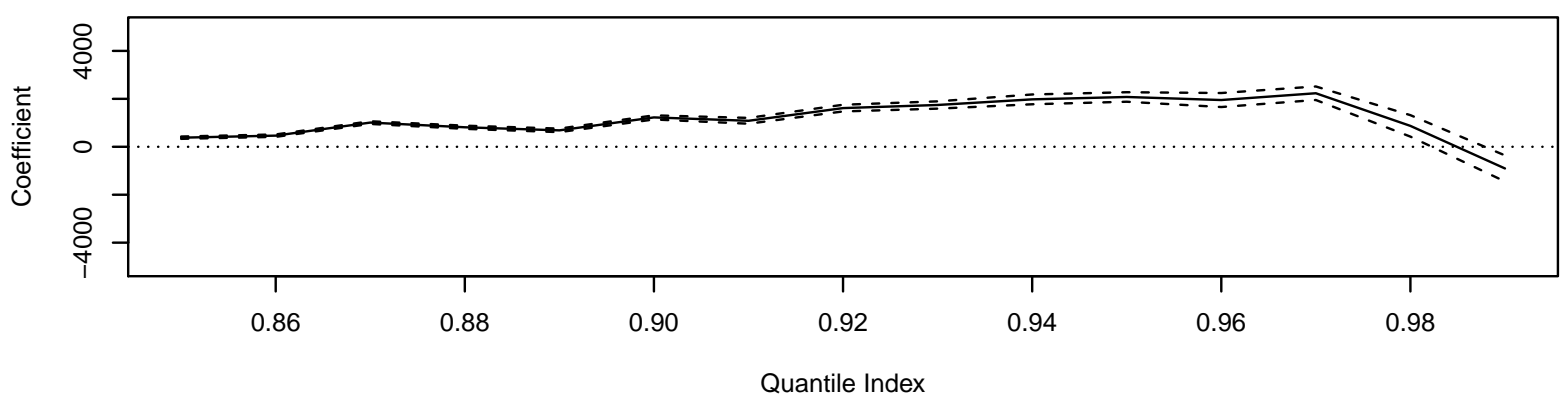

East (Age at German Reunification: <16)

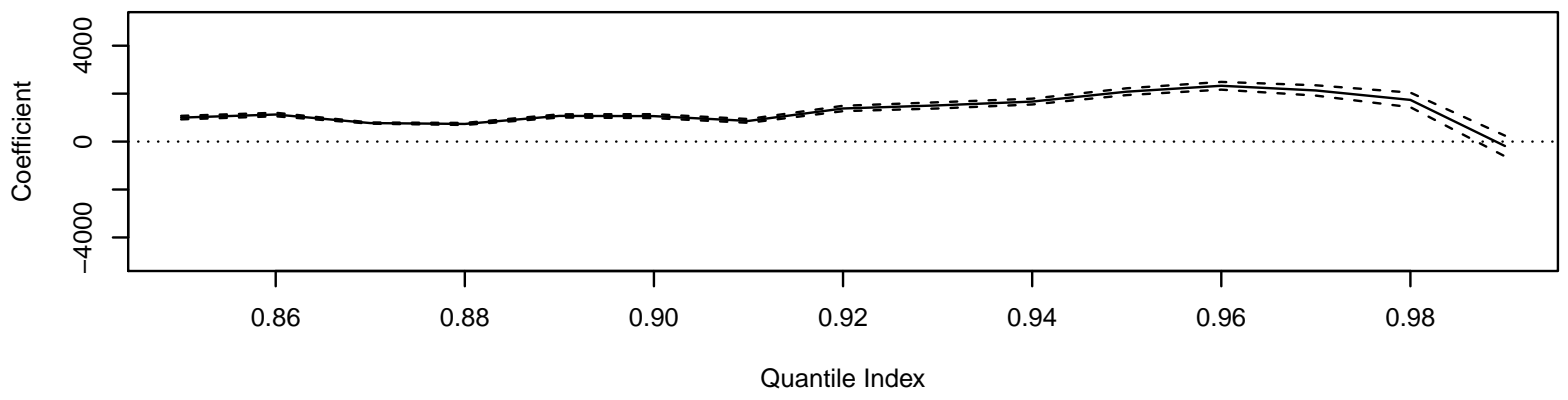

Figure 5: Institutional Impact on Risky Internal Asset Holding for Different Age Groups 
behavior of savings bank customers. We find two major results.

First, the decision to hold risky assets at the extensive margin is influenced by the institutional past, however, the remaining differences are not large. More precisely, we find West Germans to exhibit a higher probability to invest in external risky assets while East Germans have a higher probability to invest in risky assets, managed by their savings bank. This result is broadly in line with the analysis of Fuchs-Schündeln and Haliassos (2013), derived from survey data.

Second, we find more pronounced differences in the decision, how many assets a bank customer holds. After controlling for differences in gross financial wealth and liabilities, West Germans still hold significantly more external risky assets than their East German counterparts. Moreover, the difference to the East Germans increases in the conditional level of risky external asset holdings. The opposite holds true for risky assets managed by the savings bank. Here, East Germans hold higher levels of assets. However, in the highest conditional quantiles the effect reverses.

We interpret our findings as an indication that the effects of informal institutions on portfolio behaviour are quite persistent, as the study bases on data which were collected 15 years after German reunification. While the decision to hold risky assets at the extensive margin has converged for all bank customers, there are still significant and sizable differences in the decision to hold risky assets at the intensive margin. This finding indicates that the effects of reforms of formal institutions are more persistent as the results presented in Osili and Paulson (2008) seem to imply. Different from Osili and Paulson's (2008) study of U.S. immigrants we study the portfolio behaviour of individuals which experienced a strong institutional change within their country of origin. These individuals live among individuals which themselves are unexperienced with the new institutions. Thus, they primarily communicate with individuals having very similar experiences and also similar informal institutions. Moreover, their peer groups turn out to be very similar to themselves. It seems that these circumstances tend to delay the change in informal institutions, at least in as far as the intensive decision to hold risky assets is concerned.

Our findings have important implications for financial development of countries reforming their formal and especially their economic institutions. While formal institutions can be changed quite quickly, informal institutions turn out to be highly persistent. The example of Germany is a fruitful lesson in this respect. When Germany was reunified in 1990, West Germany was among the financially and economically most well developed countries. Soon after German Reunification almost all formal institutions were transferred to East Germany. However, although East Germany thus faced a highly favourable starting position into the process of transformation, our results indicate that the informal institutions prevailing in East Germany still differ to a significant extent from those in West Germany 15 years after reunification. Since the earlier presented empirical evidence indicates that informal institutions are passed along to later generations, we should expect these informal institutions to change only very slowly. Transformation (or more general reform) countries with less favourable starting positions and later starting points of their transformation processes will need long periods of time before the degree of stock market capitalization will reach similar levels as in traditional market economies. According to the World Bank Global Financial Development Database 
most East European transformation countries show much lower degrees of stock market capitalization than developed OECD countries. While average stock market capitalization amounted to $51 \%$ in high income countries in 2011, only Croatia (38\%) and Poland (32\%) reached levels above 30\%. Other transformation countries such as Serbia (22\%), the Ukraine (20\%), Hungary (20\%) or the Czech Republic (17\%) are still well below these levels and even others such as the Baltic states Lithuania (12\%), Estonia (9\%) and Latvia (4\%) exhibit only very low levels of stock market capitalization. Similarly, the markets for other financial instruments are still much less developed as in high income countries. ${ }^{34}$ As all these countries changed their formal institutions toward market economies and opened up financial markets, the previously reported findings indicate that the prevailing and highly persistent informal institutions are an important obstacle for their quick financial development.

\footnotetext{
${ }^{34}$ Beckmann, Hake and Urvova (2013).
} 


\section{References}

Acemoglu, D., S. Johnson, and J. Robinson (2001). The colonial origins of comparative development: An empirical investigation. American Economic Review 91, 1369-1401.

Acemoglu, D., S. Johnson, and J. Robinson (2005). Institutions as a cause of long-run growth. In P. Aghion and S. Durlauf (Eds.), Handbook of Economic Growth, Volume 1, Chapter 6, pp. 385-472. Elsevier.

Alan, S. (2006). Entry costs and stock market participation over the life cycle. Review of Economic Dynamics 9, 588-611.

Alesina, A. and N. Fuchs-Schündeln (2007). Good-bye Lenin (or not?): The effect of communism on people's preferences. American Economic Review 97(4), 1507-1528.

Ameriks, J. and S. Zeldes (2004). How do household portfolio shares vary with age? Columbia University Working Paper.

Andrews, M. (2013). The limits of institutional reform in development: Changing rules for realistic solutions. Cambridge University Press.

Barber, B. and T. Odean (2001). Boys will be boys: Gender, overconfidence, and common stock investment. Quarterly Journal of Economics 116(1), 261-292.

Barro, R. (1996). Institutions and growth. An introductory essay. Journal of Economic Growth 1(2), 145-148.

BBSR (2009). Raumordnungsprognose 2025/2050. Technical report, Federal Institute for Research on Building, Urban Affairs and Spatial Development, Germany.

Becker, I., M. Frick, R. Grabka, R. Hauser, P. Krause, and G. Wagner (2003). A comparison of the main household income surveys for Germany:

EVS and SOEP. In R. Hauser and I. Becker (Eds.), Reporting on Income Distribution and Poverty, pp. 55-90. Springer Publishers.

Beckmann, E., M. Hake, and J. Urvova (2013). Determinants of households' savings in Central, Eastern and Southeastern Europe. Focus on European Economic Integration 3, 8-29.

Bertaut, C. and M. Starr-McCluer (2002). Household portfolios in the United States. In L. Guiso, M. Haliassos, and T. Jappelli (Eds.), Household Portfolios, pp. 181-217. MIT Press.

Bilias, Y., D. Georgarakos, and M. Haliassos (2013). Equity culture and the distribution of wealth. Working Paper Version.

Börsch-Supan, A., M. Coppola, L. Essig, A. Eymann, and D. Schunk (2009). The German SAVE study: Design and results. Mannheim: MEA.

Börsch-Supan, A. and A. Eymann (2002). Household portfolios in Germany. In L. Guiso, M. Haliassos, and T. Jappelli (Eds.), Household portfolios, pp. 291-430. MIT Press.

Brunnermeier, M. and S. Nagel (2008). Do wealth fluctuations generate time-varying risk aversion? Micro-evidence on individuals' asset allocation. American Economic Review 98(3), 713-736.

Calvet, L., J. Campbell, and P. Sodini (2007). Down or out: Assessing the welfare costs of household investment mistakes. Journal of Political Economy 115(5), 707-747.

Campbell, J. (2006). Household finance. Journal of Finance 61(4), 1553-1604.

Carroll, C. (2002). Portfolios of the rich. In L. Guiso, M. Haliassos, and T. Jappelli (Eds.), Household Portfolios, pp. 389-429. MIT Press.

Chernozhukov, V. and H. Hong (2002). Three-step censored quantile regression and extramarital affairs. Journal of the American Statistical Association 97, 872-882.

Chinn, M. and H. Ito (2006). What matters for financial development? Capital controls, institutions, and interactions. Journal of Development Economics 81, 163-192.

Christelis, D., D. Georgarakos, and M. Haliassos (2011). Stockholding: Participation, location, and spillovers. Journal of Banking $\mathcal{G}$ Finance 35(8), 1918-1930.

Christelis, D., D. Georgarakos, and M. Haliassos (2013). Differences in portfolios across countries: Economic environment versus household characteristics. Review of Economics and Statistics 95(1), 220-236.

Christelis, D., T. Jappelli, and M. Padula (2010). Cognitive abilities and portfolio choice. European Economic Review 54(1), 18-38.

Cocco, J. (2005). Portfolio choice in the presence of housing. Review of Financial Studies 18(2), 535-567.

Dierkes, M., A. Klos, and T. Langer (2011). A note on representativeness and household finance. Economics Letters 113(1), 62-64. 
Fack, G. and C. Landais (2010). Are tax incentives for charitable giving efficient? Evidence from France. American Economic Journal: Economic Policy 2(2), 117-141.

Fitzenberger, B. (1997). Computational aspects of censored quantile regression. In Y. Dodge (Ed.), Proceedings of the 3rd International Conference on Statistical Data Analysis Based on the LI-Nom and Related Methods, Hayward, CA, pp. 171-186. IMS.

Fitzenberger, B. and P. Winkler (2007). Improving the computation of censored quantile regressions. Computational Statistics $\mathcal{E}$ Data Analysis 52(1), 88-108.

Fuchs-Schündeln, N. and M. Haliassos (2013). The role of product familiarity in household financial behavior. Working Paper Version.

Georgarakos, D., M. Haliassos, and G. Pasini (forthcoming). Household debt and social interactions. Review of Financial Studies.

Georgarakos, D. and G. Pasini (2011). Trust, sociability, and stock market participation. Review of Finance 15(4), 693-725.

Gomes, F. and A. Michaelides (2003). Portfolio choice with internal habit formation: A life-cycle model with uninsurable labor income risk. Review of Economic Dynamics 6(4), 729-766.

Gomes, F. and A. Michaelides (2005). Optimal life-cycle asset allocation: Understanding the empirical evidence. Journal of Finance 60(2), 869-904.

Guiso, L., M. Haliassos, and T. Jappelli (Eds.) (2002). Household portfolios. Cambridge/Massachusetts: MIT Press.

Guiso, L., M. Haliassos, and T. Jappelli (2003). Household stockholding in Europe: Where do we stand and where do we go? Economic Policy 18(36), 123-170.

Guiso, L. and T. Jappelli (2005). Awareness and stock market participation. Review of Finance 9(4), 537-567.

Guiso, L., T. Jappelli, and D. Terlizzese (1996). Income risk, borrowing constraints, and portfolio choice. American Economic Review 86(1), $158-172$.

Guiso, L., P. Sapienza, and L. Zingales (2004). The role of social capital in financial development. American Economic Review 94(3), 526-556.

Guiso, L., P. Sapienza, and L. Zingales (2008). Trusting the stock market. Journal of Finance 63(6), 2557-2600.

Guiso, L. and P. Sodini (2012). Household finance: An emerging field. In G. Constantinides, M. Harris, and R. Stulz (Eds.), Handbook of Economics and Finance, pp. 1397-1532. Elsevier.

Hackethal, A., M. Haliassos, and T. Jappelli (2012). Financial advisors: A case of babysitters? Journal of Banking $\mathcal{F}$ Finance 36(2), $509-524$.

Haliassos, M. (2008). Household portfolios. In S. Durlauf and L. Blume (Eds.), New Palgrave Dictionary of Economics. Palgrave Macmillian.

Haliassos, M. and C. Bertaut (1995). Why do so few hold stocks? Economic Journal 105(432), 1110-29.

Hasan, I., P. Wachtel, and M. Zhou (2009). Institutional development, financial deepening and economic growth: Evidence from China. Journal of Banking E Finance 33, 157-170.

He, X. and F. Hu (2002). Markov chain marginal bootstrap. Journal of the American Statistical Association 97, 783-795.

Heaton, J. and D. Lucas (2000). Portfolio choice and asset prices: The importance of entrepreneurial risk. Journal of Finance 55(3), 1163-1198.

Hochguertel, S. (2003). Precautionary motives and portfolio decisions. Journal of Applied Econometrics 18(1), 61-77.

Hong, H., J. Kubik, and J. Stein (2004). Social interaction and stock-market participation. Journal of Finance 59(1), $137-163$.

King, M. and J. Leape (1998). Wealth and portfolio composition: Theory and evidence. Journal of Public Economics 69(2), 155-193.

Knack, S. and P. Keefer (1995). Institutions and economic performance. Cross country tests using alternative institutional measures. Economics $\mathcal{E}$ Politics 7(3), 207-227.

Knack, S. and P. Keefer (1997). Why don't poor countries catch up? A cross-national test of an institutional explanation. Economic Inquiry 35, $590-602$.

Koenker, R. and G. Bassett (1978). Regression quantiles. Econometrica 46, 33-50.

Koenker, R. and K. Hallock (2001). Quantile regression: An introduction. Journal of Economic Perspectives 15(4), 43-56.

LaPorta, R., F. L. de Silanes, A. Shleifer, and R. Vishny (1999). The quality of government. Journal of Law, Economics E Organization 15, $222-279$.

Levine, R. (1997). Financial development and growth. Journal of Economic Literature 35, 688-726.

Levine, R. (1998). Stock markets, banks, and economic growth. American Economic Review 88, 537-558. 
Malmendier, U. and S. Nagel (2011). Depression babies: Do macroeconomic experiences affect risk taking? Quarterly Journal of Economics 126(1), 373-416.

Merton, R. (1969). Lifetime portfolio selection under uncertainty: The continuous time case. Review of Economics and Statistics 51, $247-257$.

Miniaci, R. and G. Weber (2002). Econometric issues in the estimation of household portfolio models. In L. Guiso, M. Haliassos, and T. Jappelli (Eds.), Household Portfolios, pp. 143-178. MIT Press.

North, D. and R. Thomas (1973). The rise of the Western world: A new economic history. Cambridge University Press.

Osili, U. and A. Paulson (2008). Institutions and financial development: Evidence from international migrants in the United States. Review of Economics and Statistics 90(3), 498-517.

Portnoy, S. and R. Koenker (1997). The gaussian hare and the Laplacian tortoise: Computability of squared-error versus absolute-error estimators with discussion. Statistical Science 12(4), 279-300.

Powell, J. (1984). Least absolute deviations estimation for the censored regression model. Journal of Econometrics 25(3), 303-325.

Powell, J. (1986). Censored regression quantiles. Journal of Econometrics 32, 143-155.

Rodrik, D., A. Subramanian, and F. Trebbi (2004). Institutions rule: The primacy of institutions over geography and integration in economic development. Journal of Economic Growth 9(2), 131-165.

Rosen, H. and S. Wu (2004). Portfolio choice and health status. Journal of Financial Economics 72(3), 457-484.

Rousseau, P. and P. Wachtel (2000). Equity market and growth: Cross country evidence on timing and outcomes. Journal of Banking $\mathcal{E}$ Finance 24, 1933-1957.

Rousseau, P. and S. Xiao (2007). Banks, stock markets and China's great leap forward. Emerging Markets Review 8(3), $206-211$.

Schunk, D. (2007). The German SAVE survey 2001/2006. Documentation and methodology. Technical report, Technical Discussion Paper Sonderforschungsbereich 504, University of Mannheim.

Van Rooij, M., A. Lusardi, and R. Alessie (2011). Financial literacy and stock market participation. Journal of Financial Economics 101(2), $449-472$.

Vissing-Jorgensen, A. (2002). Towards an explanation of household portfolio choice heterogeneity: nonfinancial income and participation cost structures. Review of Economic Dynamics 9, 588-611.

Wachter, J. and M. Yogo (2010). Why do household portfolio shares rise in wealth? Review of Financial Studies 23(11), 3929-3965.

Williamson, O. (1996). The mechanics of governance. New York: Oxford University Press. 